\title{
An Updated Nuclear Criticality Slide Rule
}

Functional Slide Rule

Manuscript Completed: February 1997

Date Published: April 1998

Prepared by

C.M. Hopper, B. L. Broadhead

Oak Ridge National Laboratory

Managed by Lockheed Martin Energy Research Corporation

Oak Ridge, TN 37831-6370

M.L. Thomas, NRC Project Manager

Prepared for

Division of Regulatory Applications

Office of Nuclear Regulatory Research

U.S. Nuclear Regulatory Commission

Washington, DC 20555-0001

NRC Job Code W6303

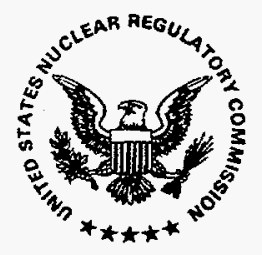




\section{DISCLAIMER}

Portions of this document may be illegible electronic image products. Images are produced from the best available original document. 


\begin{abstract}
This Volume 2 contains the functional version of the updated nuclear criticality slide rule (more accurately, sliding graphs) that is referenced in An Updated Nuclear Criticality Slide Rule: Technical Basis, NUREG/CR6504, Vol. 1 (ORNL/TM-13322/V1). This functional slide rule provides a readily usable "in-hand" method for estimating pertinent nuclear criticality accident information from sliding graphs, thereby permitting (1) the rapid estimation of pertinent criticality accident information without laborious or sophisticated calculations in a nuclear criticality emergency situation, (2) the appraisal of potential fission yields and external personnel radiation exposures for facility safety analyses, and (3) a technical basis for emergency preparedness and training programs at nonreactor nuclear facilities. The slide rule permits the estimation of neutron and gamma dose rates and integrated doses based upon estimated fission yields, distance from the fission source, and time-after criticality accidents for five different critical systems. Another sliding graph permits the estimation of critical solution fission yields based upon fissile material concentration, critical vessel geometry, and solution addition rate. Another graph provides neutron and gamma dose-reduction factors for water, steel, and concrete. Graphs from historic documents are provided as references for estimating critical parameters of various fissile material systems. Conversion factors for various English and metric units are provided for quick reference.
\end{abstract}





\section{CONTENTS}

Page

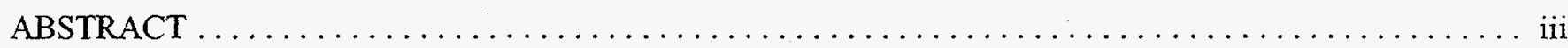

LIST OF FIGURES $\ldots \ldots \ldots \ldots \ldots \ldots \ldots \ldots \ldots \ldots \ldots \ldots \ldots \ldots \ldots \ldots \ldots \ldots \ldots \ldots \ldots \ldots \ldots \ldots \ldots$

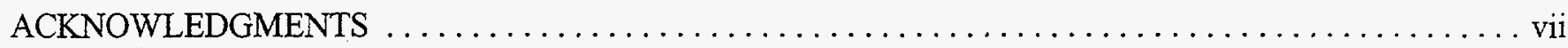

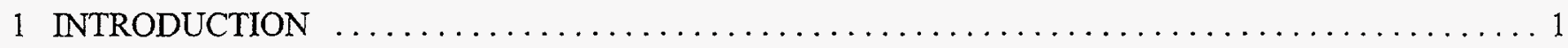

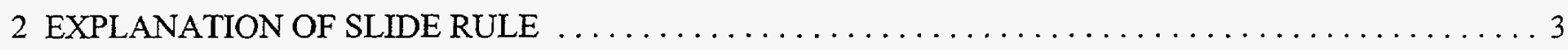

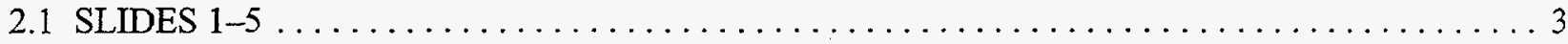

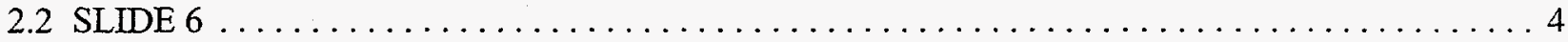

2.3 CONVERSION FACTORS AND EQUALITIES $\ldots \ldots \ldots \ldots \ldots \ldots \ldots \ldots \ldots \ldots \ldots \ldots \ldots \ldots$

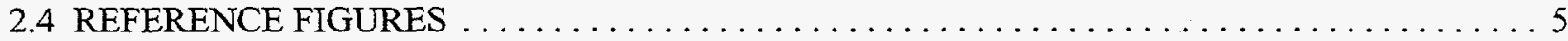

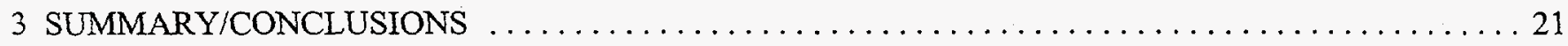

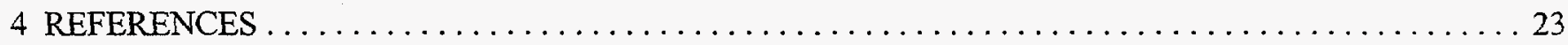

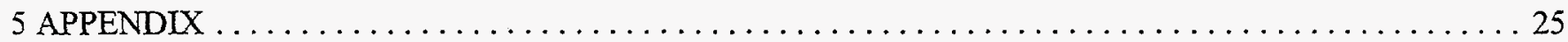




\section{LIST OF FIGURES}

Figure

Page

$1 \quad$ Dose reduction factors for various shield thicknesses $\ldots \ldots \ldots \ldots \ldots \ldots \ldots \ldots \ldots \ldots \ldots \ldots$

$2 \quad \mathrm{LEU} \mathrm{UO}_{2}-\mathrm{H}_{2} \mathrm{O}$ critical sphere volume $(\mathrm{L})$ vs uranium mass $(\mathrm{kg}) \ldots \ldots \ldots \ldots \ldots \ldots \ldots \ldots \ldots$

$3 \quad \mathrm{LEU} \mathrm{UO} \mathrm{O}_{2}-\mathrm{H}_{2} \mathrm{O}$ critical sphere diameter (in.) vs uranium density $(\mathrm{g} / \mathrm{L}) \ldots \ldots \ldots \ldots \ldots$

$4 \quad \mathrm{LEU} \mathrm{UO}_{2}-\mathrm{H}_{2} \mathrm{O}$ critical sphere uranium mass $(\mathrm{kg})$ vs uranium density $(\mathrm{g} / \mathrm{L}) \ldots \ldots \ldots \ldots \ldots$

$5 \quad \mathrm{LEU} \mathrm{UO} \mathrm{O}_{2}-\mathrm{H}_{2} \mathrm{O}$ critical infinite cylinder uranium linear density $(\mathrm{kg} / \mathrm{ft}$ ) vs diameter (in.) $\ldots \ldots \ldots 10$

$6 \quad$ LEU UO $\mathrm{U}_{2}-\mathrm{H}_{2} \mathrm{O}$ critical infinite cylinder diameter (in.) vs uranium density $(\mathrm{g} / \mathrm{L}) \ldots \ldots \ldots \ldots$

$7 \quad \mathrm{LEU} \mathrm{UO} \mathrm{U}_{2}-\mathrm{H}_{2} \mathrm{O}$ critical infinite slab uranium areal density $\left(\mathrm{kg} / \mathrm{ft}^{2}\right)$ vs thickness (in.) $\ldots \ldots \ldots \ldots 12$

$8 \quad$ LEU $\mathrm{UO}_{2}-\mathrm{H}_{2} \mathrm{O}$ critical infinite slab thickness (in.) vs uranium density $(\mathrm{g} / \mathrm{L}) \ldots \ldots \ldots \ldots \ldots \ldots$

$9 \quad \mathrm{HEU} \mathrm{UO} \mathrm{UO}_{2}\left(\mathrm{NO}_{3}\right)_{2}-\mathrm{H}_{2} \mathrm{O}$ critical sphere volume $(\mathrm{L})$ vs uranium mass $(\mathrm{kg}) \ldots \ldots \ldots \ldots \ldots$

$10 \mathrm{HEU} \mathrm{UO} \mathrm{UO}_{2}\left(\mathrm{NO}_{3}\right)_{2}-\mathrm{H}_{2} \mathrm{O}$ critical sphere uranium mass $(\mathrm{kg})$ vs uranium density $\left(\mathrm{g} / \mathrm{cm}^{3}\right) \ldots \ldots \ldots$

$11 \mathrm{HEU} \mathrm{UO} \mathrm{UO}_{2}\left(\mathrm{NO}_{3}\right)_{2}-\mathrm{H}_{2} \mathrm{O}$ critical sphere diameter (in.) vs uranium density $\left(\mathrm{g} / \mathrm{cm}^{3}\right) \ldots \ldots \ldots$

$12 \mathrm{HEU} \mathrm{UO}_{2}\left(\mathrm{NO}_{3}\right)_{2}-\mathrm{H}_{2} \mathrm{O}$ critical infinite cylinder diameter (in.) vs uranium density $\left(\mathrm{g} / \mathrm{cm}^{3}\right) \ldots \ldots$

$13 \mathrm{HEU} \mathrm{UO} \mathrm{UO}_{2}\left(\mathrm{NO}_{3}\right)_{2}-\mathrm{H}_{2} \mathrm{O}$ critical cylinder uranium linear density $(\mathrm{kg} / \mathrm{ft})$ vs diameter (in.) $\ldots \ldots \ldots 18$

$\left.14 \quad \mathrm{HEU} \mathrm{UO} \mathrm{NO}_{3}\right)_{2}-\mathrm{H}_{2} \mathrm{O}$ critical slab uranium areal density $\left(\mathrm{kg} / \mathrm{ft}^{2}\right)$ vs thickness (in.) $\ldots \ldots \ldots \ldots$

$15 \quad \mathrm{HEU} \mathrm{UO} \mathrm{UO}_{2}\left(\mathrm{NO}_{3}\right)_{2}-\mathrm{H}_{2} \mathrm{O}$ critical slab thickness (in.) vs uranium density $\left(\mathrm{g} / \mathrm{cm}^{3}\right) \ldots \ldots \ldots \ldots$ 


\section{ACKNOWLEDGMENTS}

The authors acknowledge the support and encouragement given by M. L. Thomas, NRC Project Manager of the Office of Nuclear Regulatory Research, Division of Regulatory Applications. The contributions of the reviewers, D. R. Damon, C. W. Nilsen, and M. L. Thomas of the U.S. Nuclear Regulatory Commission, H. L. Dodds of the University of Tennessee, T. P. McLaughlin of Los Alamos National Laboratory, and K. S. Gant, J. V. Pace III, C. V. Parks, and R. M. Westfall of Oak Ridge National Laboratory are appreciated. The guidance of M. D. DeHart and the work of P. B. Fox in the generation of the very detailed slide-rule plots are gratefully acknowledged. Finally, the authors express their thanks to Lindy Norris and Willena Carter who prepared the draft, final manuscript, and electronic version of the document. 


\section{INTRODUCTION}

To perform safety analyses and to develop and maintain a program of emergency preparedness and response for nonreactor nuclear facilities that process fissile materials, it is necessary to hypothesize credible magnitudes of nuclear criticality accidents, potential personnel hazards, and safe corrective actions in the event of a nuclear criticality accident. In an effort to provide general technical information that relates to these requirements, this functional updated nuclear criticality slide rule (more accurately, sliding graphs) extends the capabilities of the original slide rule design ${ }^{1}$ to include five different unreflected fissile material systems. Systems were selected for their potential relevance to U.S. Nuclear Regulatory Commission (NRC) licensed nuclear fuel cycle facilities fissile materials; that is,

1. Solution of $\mathrm{U}(93.2) \mathrm{O}_{2}\left(\mathrm{NO}_{3}\right)_{2} @ \mathrm{H}^{235} \mathrm{U}=500$

2. U(93.2) metal

3. Damp U(93.2) $)_{3} \mathrm{O}_{8} @ \mathrm{H}^{235} \mathrm{U}=10$

4. Damp U(4.95) $\mathrm{O}_{2} \mathrm{~F}_{2} @ \mathrm{H}^{235} \mathrm{U}=410$

5. Damp U(5) $\mathrm{O}_{2} @ \mathrm{H}^{235} \mathrm{U}=200$

The purpose of the "slide rule" is to provide variably interrelated nuclear criticality accident information about the following:

- fission yield magnitude estimation (based upon personnel or field radiation measurements or various critical system parameter inputs);

- direct and indirect ("skyshine") prompt neutron- and gamma-radiation dose estimates at variable distances from the accident;

- time-integrated radiation dose estimates at variable distances from and time after the fission yield;

- fission-product, decay-gamma dose rates at variable distances from and time after the fission yield;

- 1-min fission-product, decay-gamma radiation dose integrals at variable distances from and time after the fission yield; and

- dose-reduction factors for variable thicknesses of steel, concrete, and water.

Reference graphs of shielding dose-reduction factors (Figure 1) and various critical systems (Figures 2-15) are provided. The functional slide rule is included in the Appendix to this Vol. 2 as six pages of sliding graphs (Slides 1-6), followed by some conversion factors and equalities. This information is provided within this brief document that is easily "hand-held" for (1) the rapid estimation of pertinent criticality accident information without laborious or sophisticated calculations in a nuclear criticality emergency situation, (2) the appraisal of potential fission yields and external personnel radiation exposures for facility safety analyses, and (3) the development of emergency preparedness and training programs at nonreactor nuclear facilities. 



\section{EXPLANATION OF SLIDE RULE}

This revised slide rule includes 6 sliding graphs, Slides 1-6; 15 nonsliding graphs, Figures 1-15; and a list of conversion factors and equalities. Five sliding graphs, Slides $1-5$, provide interrelated data for five different types of critical systems. One sliding graph, Slide 6, permits the estimation of first-pulse fission yields for highenriched uranium [(HEU); i.e., $93 \mathrm{wt} \%{ }^{235} \mathrm{U}$ in uranium] solutions and for low-enriched uranium [(LEU); i.e., $5 \mathrm{wt} \%{ }^{235} \mathrm{U}$ in uranium] solutions and damp oxides. The list of conversion factors and equalities, as well as the nonsliding Figures 1-15, are provided for reference. Figure 1 provides neutron and gamma dose-reduction factors for various thicknesses of water, steel, and concrete shielding. Figures 2-15 provide low- and highenriched uranium and water-critical parameters (i.e., mass, volume, uranium densities, sphere and infinitely long cylinder diameters, and infinite slab thicknesses, etc.) from an historic reference. ${ }^{2}$

As described in Vol. 1, Slides 1-5 were developed for bare critical systems having neutron- and gamma-leakage characteristics of the specified materials in the slide titles. Each of the two-dimensional (2-D) radiation-transport calculations were performed with the radiation sources located $1 \mathrm{~m}$ above the air-over-ground plane interface. The resulting doses and dose rates were calculated at various distances from the radiation source but also $1 \mathrm{~m}$ above the same air-over-ground plane interface. The intent of modeling the calculations in this manner was to simulate a criticality accident in an unshielded process environment that could be used to estimate the dose (rate) values to people at various distances from an accident.

As readily noticed, there is an abundance of mixed English and metric units used throughout the slide rule to accommodate historic and typical use in the U.S. industry. Historically, nonreactor nuclear facilities were built to English unit specifications (e.g., 50,000-gal tank, 16-in.-diam pipes/tubes, 2-gal/min pump capacity, etc.), whereas operating process specifications have evolved to metric units (e.g., grams of $U$ or grams ${ }^{235} \mathrm{U}$ per liter of solution, $\mathrm{kg} \mathrm{U}$, grams of $\mathrm{U}$ per cubic centimeter, etc.). The unit of typical use is presented in the text, which is then followed by an alternative unit in parentheses. The intent of providing mixed units is to ease data conversion and manipulation during a potentially stressful period of emergency response when data exchange is provided in mixed units.

\subsection{SLIDES 1-5}

Though each of the Slides 1-5 is for a different system of fissile materials, the type of information presented is identical in each of the five slides. Each slide consists of five graphs. The bottom-right, vertical-logarithmic scale has an arrow pointer labeled "Fissions." The bottom-right graph is labeled "Estimated Fission Yield Based on Distant Gamma Dose Rate and Elapsed Time." The bottom-left graph is labeled "Estimated Prompt Doses Based on Total Fission Yield and Distance From Incident." The top-left graph is labeled "Integrated Total Dose (rads) Based on Estimated Fission Yield, Distance From Incident and Time." The top-right graph is labeled "Accumulated One-Minute Dose (rads) Based on Estimated Fission Yield, Distance from Incident and Time of Entry After Incident."

The estimation of dose, dose rate, and fission yield can be related in a "forward" or "backward" manner. That is to say in a forward manner, given a fission yield of some magnitude (e.g., $10^{17}$ fissions), as positioned on the bottom-right, vertical-logarithmic scale, using the bottom-left graph one can determine an unshielded distant prompt total neutron/gamma free-air rad dose at a given distance (e.g., $100 \mathrm{ft}$ ) to be about $3.5 \mathrm{rads}$ (based on Slide 1). Likewise, for an indicated $10^{17}$ fissions an integrated 1-min fission-product-gamma radiation exposure to a rescue team arriving within $20 \mathrm{ft}$ of the subcritical system, $15 \mathrm{~min}$ after the criticality occurred, can be estimated to be about 0.15 rads from the top-right graph. The estimated fission-product-gamma radiation dose rate at $100 \mathrm{ft}$ from the position of the criticality, $20 \mathrm{~min}$ after the $10^{17}$ fissions, is estimated to be about $0.32 \mathrm{rad} / \mathrm{h}$. In a backward manner using the bottom-right graph, given an unshielded $4 \mathrm{rad} / \mathrm{h}$ fission-product-gamma 
radiation dose rate field measurement at $100 \mathrm{ft}$ from the accident site, $20 \mathrm{~min}$ after the criticality accident occurred, the slide rule can be positioned to estimate the criticality yield to be about $1.2 \times 10^{18}$ fissions. Likewise, positioning the top-left graph for an unshielded total integrated neutron/gamma free-in-air dose measurement of $200 \mathrm{rad}$ at $50 \mathrm{ft}$ for $100 \mathrm{~min}$ after the criticality permits an estimated criticality accident yield of about $1.6 \times 10^{18}$ fissions. During the evolution of an emergency response (e.g., collection of radiation exposure data and field radiation dose-rate data) estimates of fission yields and radiation exposures may be improved.

As presented in the top-left graph for integrated total dose, the delayed gamma dose contributions are included beginning $1 \mathrm{~s}$ after the event. The prompt neutron and gamma contributions correspond to less than $1 \mu$ s after the event. No delayed neutron contribution nor contributions from delayed gammas between $1 \mu \mathrm{s}$ and $1 \mathrm{~s}$ were included in the dose curves.

The skyshine values from the bottom-left graph provide the skyshine component of the "total," "gamma," and "neutron" radiation doses due to the atmospheric backscattering of an upwardly directed, $90^{\circ}$ cone of radiation from the criticality accident. This information could be useful for criticality accidents that are laterally shielded (e.g., a criticality accident in a drum surrounded by equipment or other drums of nonfissioning material, thinroofed-thick-walled facility, etc.). Additionally, the ratio of the " $\gamma$ skyshine" values to total "gamma $(\gamma)$ " values can provide an estimate of totally shielded radiation doses and dose rates provided on the remaining graphs.

It can be observed from the bottom-left graph that at less than 1000-ft distances from the criticality, the " $t$ skyshine," the "n skyshine," and the " $\gamma$ skyshine" components of the unshielded "total $(t)$," "gamma $(\gamma)$," and "neutron (n)" doses are between a factor of about $1 / 3000$ th at $1 \mathrm{ft}$ to $1 / 15$ th at $1000 \mathrm{ft}$ from the criticality event. Therefore, the predominant radiation exposure comes from the forward-penetrating radiation at the air-overground interface. Depending upon the location of exposed people and the effectiveness of intervening dosereduction shielding, skyshine may or may not be a significant portion of a person's radiation exposure. Likewise, other estimates from the slide rule would need to be tempered with an understanding of potential influences of intervening shielding and skyshine.

\subsection{SLIDE 6}

Slide 6 provides the "First Pulse Fission Yield Estimates for Vertical and Horizontal Cylinders of HEU and LEU Solutions" and oxides. Slide 6 also consists of five interrelated graphs. The mid-right, vertical-logarithmic scale has an arrow pointer labeled "Addition rate (gal/min)." The top-left graph provides the "Fission Yield" for a "LEU Vertical Cylinder Diameter (in.)" based upon the uranyl nitrate solution or uranium oxide uranium density ( $\mathrm{g} \mathrm{U} / \mathrm{L}$ ) and the solution or oxide addition rate. The top-right graph provides identical information for a "LEU Horizontal Cylinder Length (in.)." The bottom-left, 2-D graph provides the fission yield for a "HEU Vertical Cylinder Diameter (in.)" based upon a uranium solution density (g U/L) and the solution addition rate. The bottom-right graph provides identical information for a "HEU Horizontal Cylinder Length (in.)."

Slide 6 may also be used in a forward or backward manner: That is, based upon a solution addition rate, solution uranium density, cylinder dimension (diameter or length) and cylinder orientation (vertical or horizontal), a fission yield may be estimated. For example, given a 30-g HEU/L addition rate of $0.4 \mathrm{gal} / \mathrm{min}$ into a 26-in.-diam vertical cylinder provides a first-pulse fission yield of about $9 \times 10^{16}$ fissions at a volume of approximately 23 gal of solution. Assuming that the given configuration will become subcritical at less than 23 gal of solution, if there is a 5-gal (i.e., 18.94-L) excess of solution, then, from the "Conversion Factors and Equalities" it will require approximately an additional $(18.94 \mathrm{~L}) \cdot\left(10^{17}\right.$ fissions $\left./ \mathrm{L}\right)$ or $1.9 \times 10^{18}$ fissions to evaporate enough water to cause 
the system to be subcritical. Alternatively, Slide 6 may be used in a backward manner by selecting a fission yield and examining the parameters resulting in that fission yield.

\subsection{CONVERSION FACTORS AND EQUALITIES}

The listing of conversion factors and equalities are provided for handy reference in the interpretation of field data or translation of the slide rule to field applications. Some guidance is provided, such as the number of fissions required to evaporate $1 \mathrm{~L}$ of room-temperature water and the number of fissions produced over a time period for a given volume of solution. Such rules-of-thumb are inherently approximate and may be influenced by complex mechanisms. However, the application of these rules-of-thumb should be accurate within about a factor of 2 .

\subsection{REFERENCE FIGURES}

Figures 1 through 15 are provided as comparative references to potential systems of interest for emergency planning, preparedness, training, and response. They may be used for approximating the radiation dose reduction due to concrete, steel, and water (Figure 1) or for approximating the critical parameters of idealized waterreflected critical systems (Figures 2 through 15 ). The figures are not included for the purpose of precisely evaluating shielding and subcritical or critical systems. Precise nuclear criticality safety evaluations for normal and credible abnormal fissile material conditions should be performed by experienced nuclear criticality safety specialists who are familiar with computational evaluations and analyses of the normal and abnormal fissile material processes that will influence the approach to the critical state.

Figure la provides the effective prompt fission neutron- and gamma-radiation, dose-reduction factors for multiple layers of a specified shielding material located at $24-\mathrm{ft}$ intervals from the criticality accident out to a distance of $240 \mathrm{ft}$. The thicknesses of the thin shielding materials considered were 1 -in. $(2.54-\mathrm{cm})$-thick layers of steel, or 3-in. (7.62-cm)-thick layers of concrete, or 3-in. (7.62-cm)-thick layers of water. The purpose of evaluating multiple thin layers of shielding materials was to simulate the effects of walls and equipment that may be intervening between operating areas of a facility. Because the dose-reduction factors are based upon coupled neutron-gamma calculations the influence of neutron-capture gammas is included in the gamma-radiation, dosereduction factor.

Figure $1 \mathrm{~b}$ provides extrapolated prompt fission neutron and delayed fission-product gamma radiation dose reduction factors for thin single shields of material (i.e., steel, concrete, or water) located approximately $10 \mathrm{ft}$ from the criticality accident. The shielding effectiveness differences from Figure la are due to the higher energy of the nearly first-collision neutrons on the shield and the lower-energy, delayed fission-product-gamma radiation not having a neutron-capture-gamma component.

Figures 2 through 15 provide approximate critical parameters for various fully water-reflected geometries (i.e., spheres, infinitely long cylinders, and slabs having infinite lateral dimensions) for water-moderated systems of low-enriched uranium (LEU $-2.5,3,4,5$, and $6 \mathrm{wt} \%{ }^{235} \mathrm{U}$ in uranium) and high-enriched uranium (HEU 93 wt $\%{ }^{235} \mathrm{U}$ in uranium). 


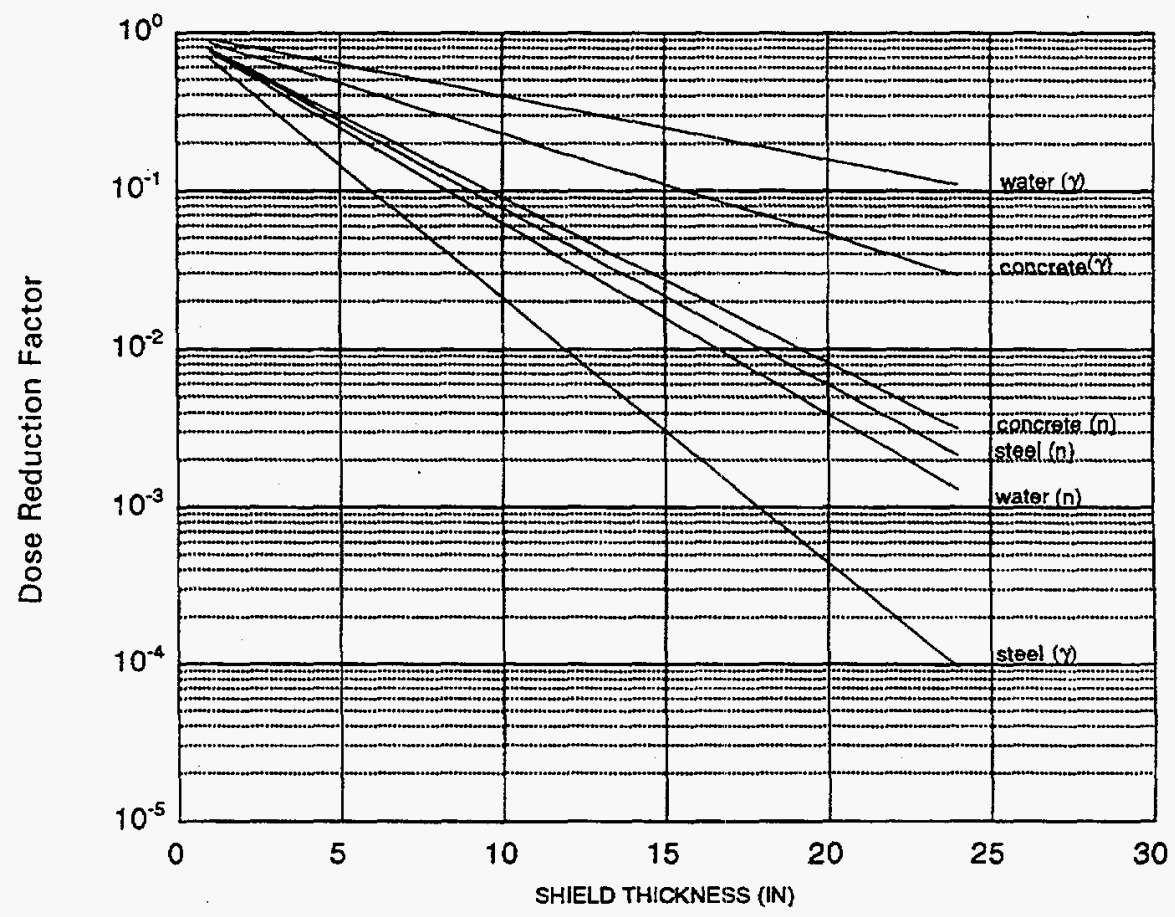

(a) prompt radiation dose-reduction factors for multiple thin shields

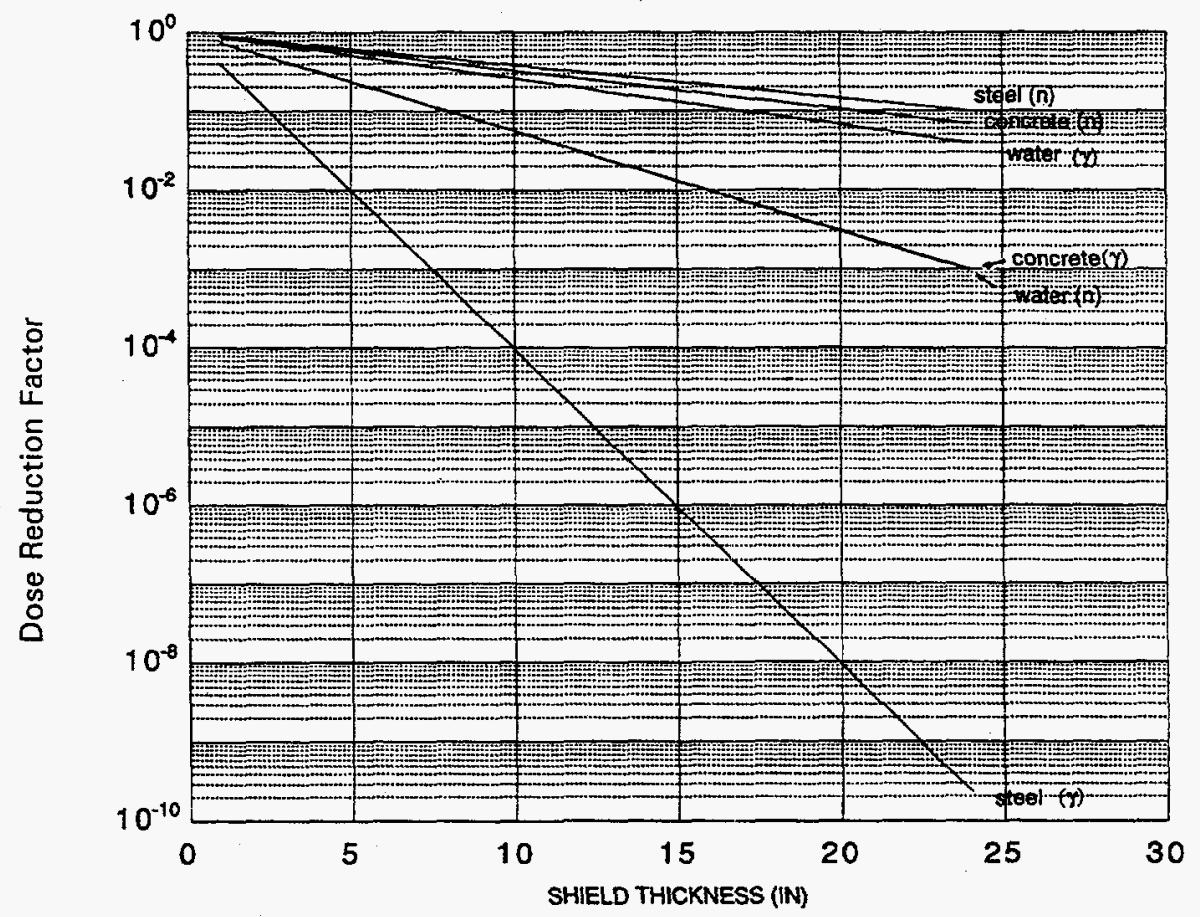

(b) prompt neutron and delayed gamma dose-reduction factors for single shields

Figure 1 Dose reduction factors for various shield thicknesses

NUREG/CR-6504,

Vol. 2 


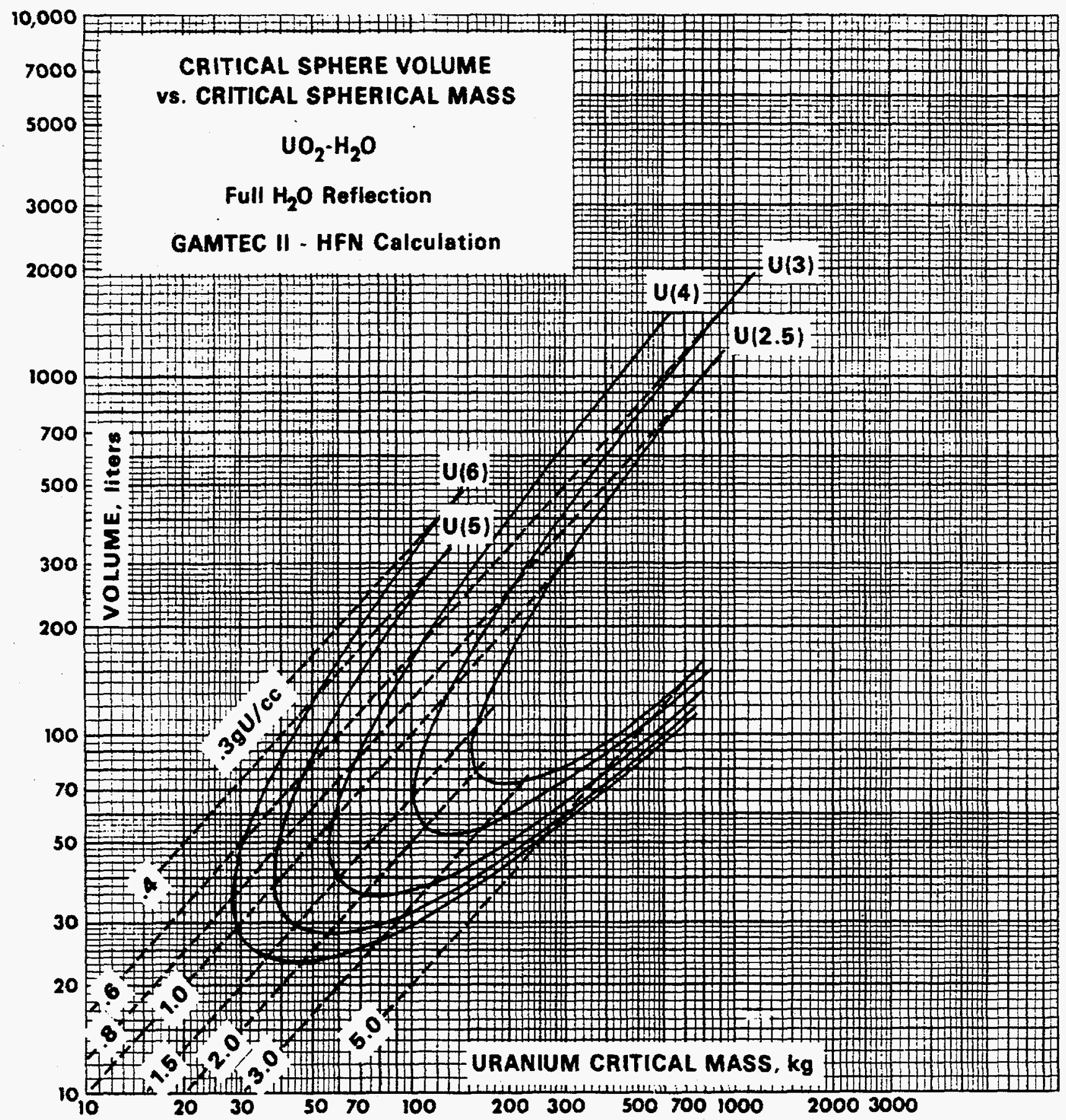

Figure 2 LEU $\mathrm{UO}_{2}-\mathrm{H}_{2} \mathrm{O}$ critical sphere volume (L) vs uranium mass $(\mathrm{kg})$ 


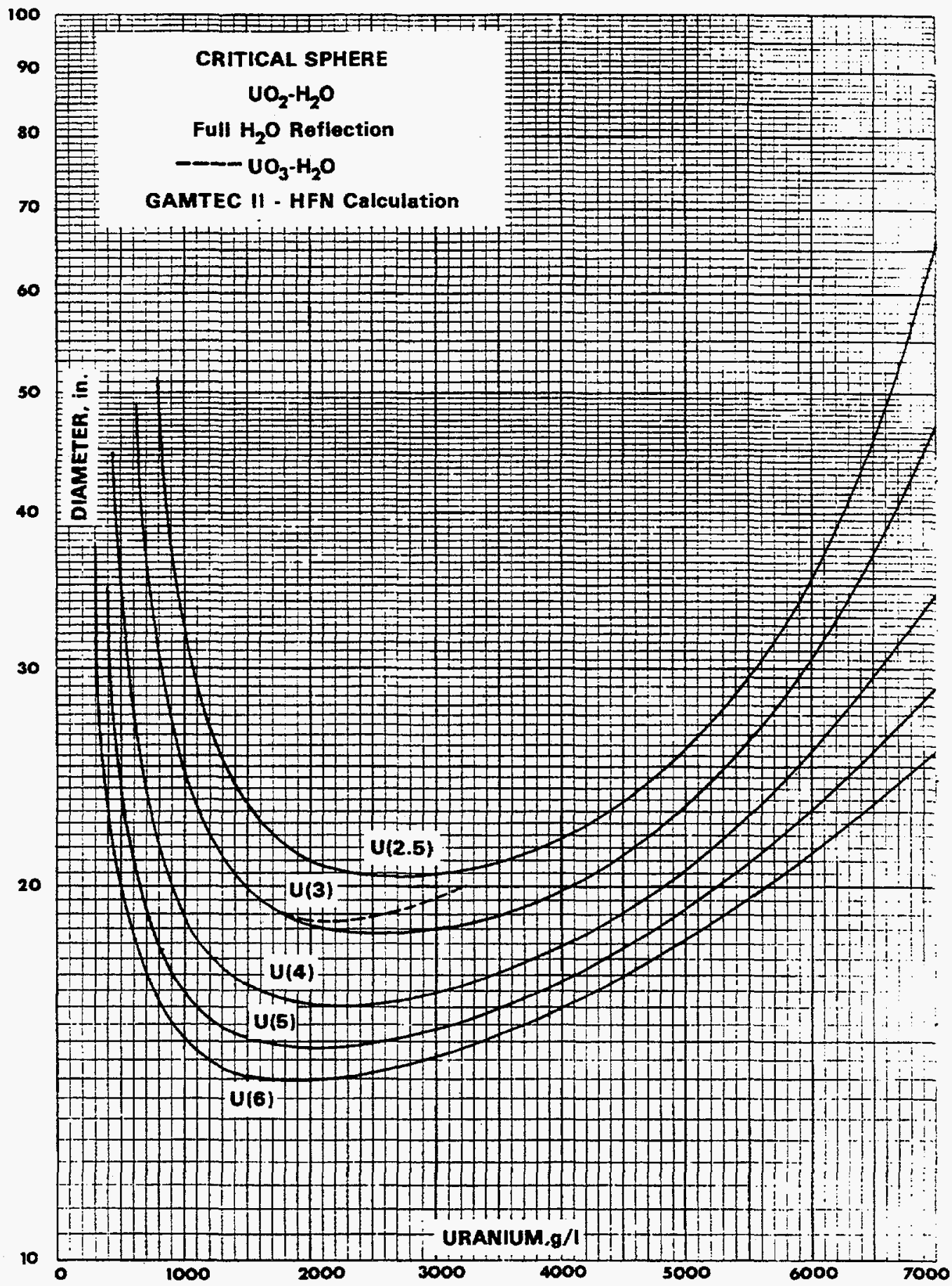

Figure $3 \mathrm{LEU} \mathrm{UO}_{2}-\mathrm{H}_{2} \mathrm{O}$ critical sphere diameter (in.) vs uranium density (g/L)

NUREG/CR-6504,

Vol. 2 
Section 2

Explanation of Slide Rule

III.B.6-6

ARH-600

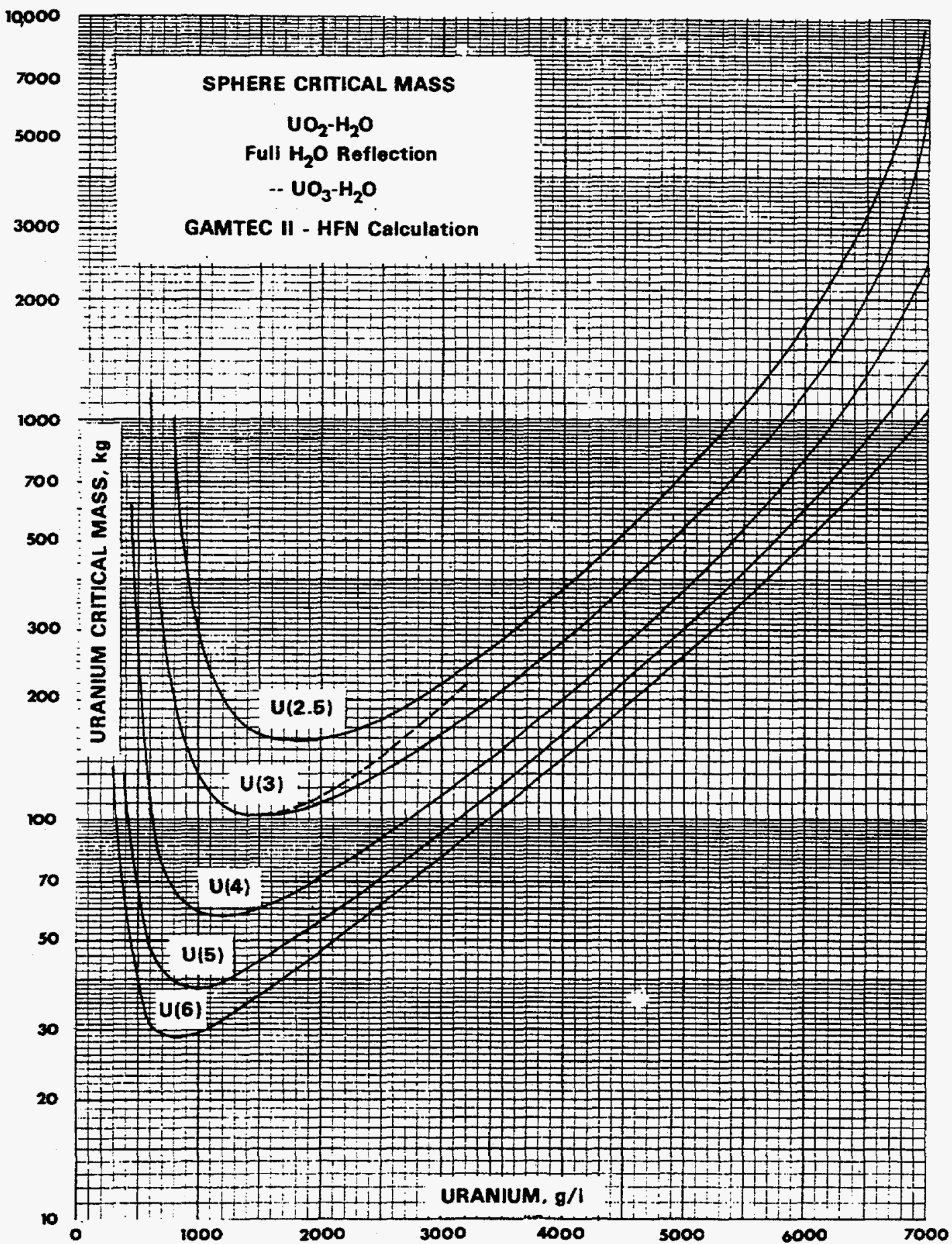

Figure 4 LEU $\mathrm{UO}_{2}-\mathrm{H}_{2} \mathrm{O}$ critical sphere uranium mass $(\mathrm{kg})$ vs uranium density $(\mathrm{g} / \mathrm{L})$

NUREG/CR-6504,

Vol. 2 


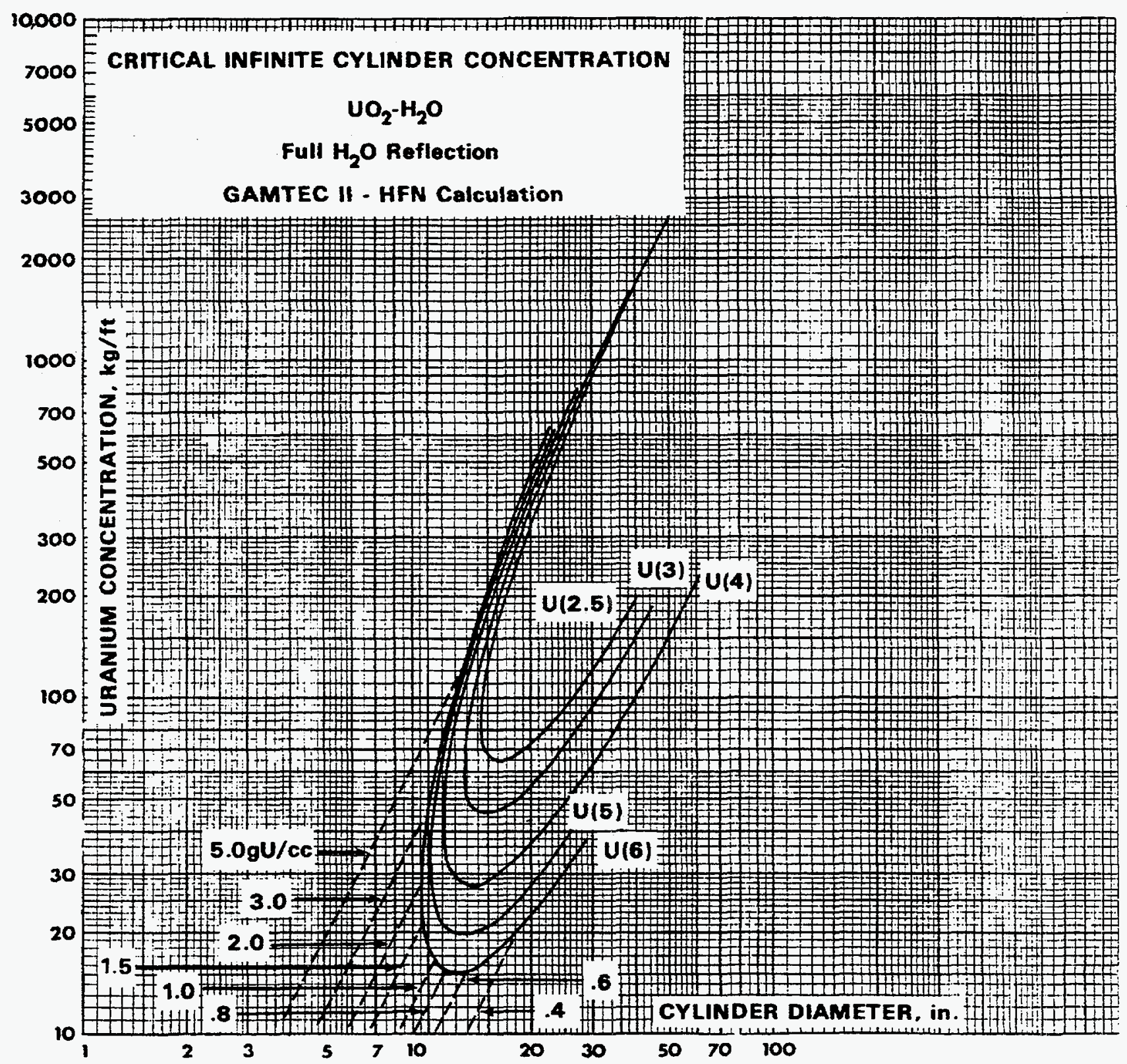

Revised:

3-19-76

Figure 5 LEU $\mathrm{UO}_{2}-\mathrm{H}_{2} \mathrm{O}$ critical infinite cylinder uranium linear density $(\mathrm{kg} / \mathrm{ft}$ ) vs diameter (in.)

NUREG/CR-6504,

Vol. 2 


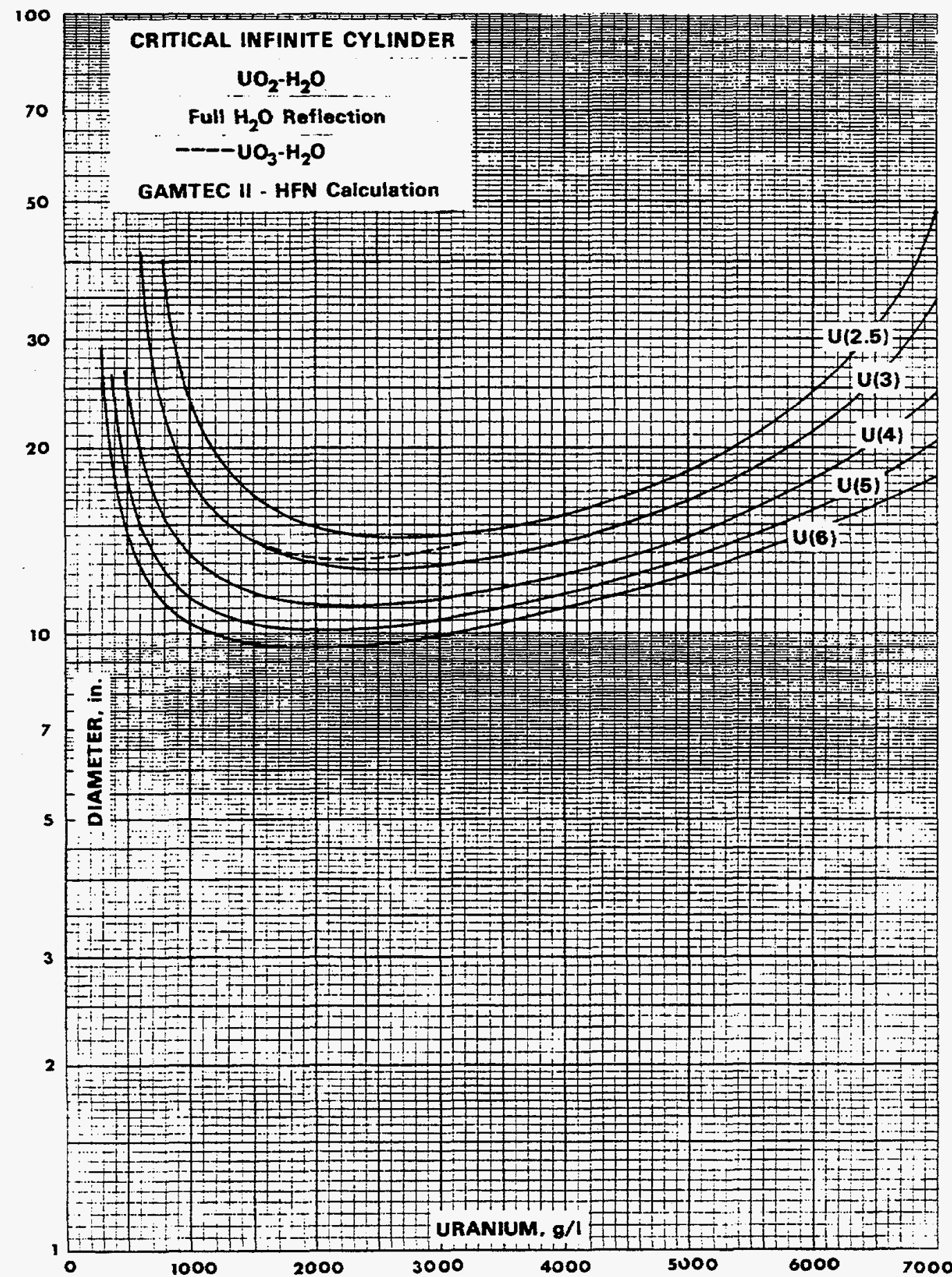

Figure $6 \mathrm{LEU} \mathrm{UO} \mathrm{O}_{2}-\mathrm{H}_{2} \mathrm{O}$ critical infinite cylinder diameter (in.) vs uranium density (g/L) 


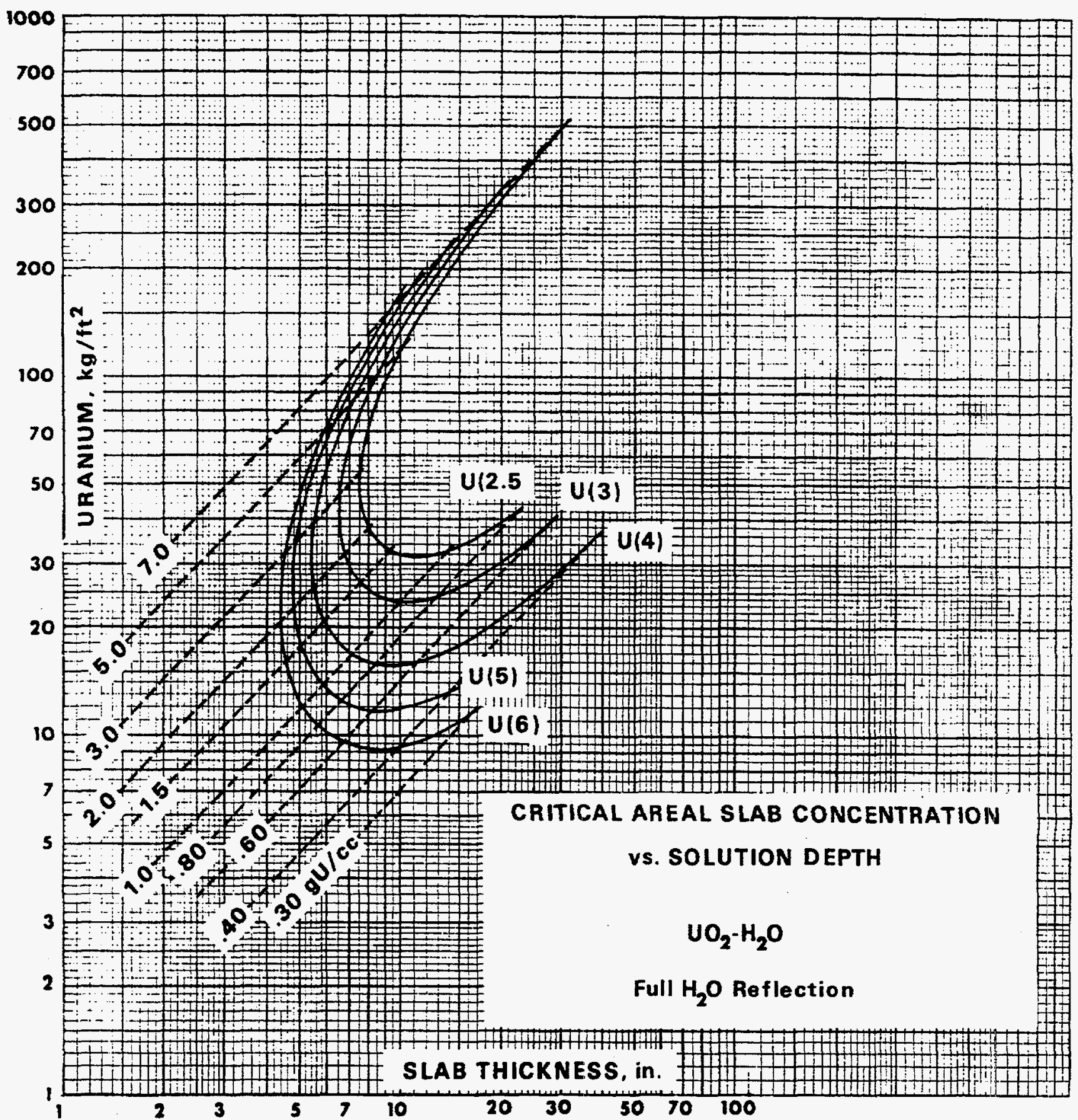

Figure 7 LEU $\mathrm{UO}_{2}-\mathrm{H}_{2} \mathrm{O}$ critical infinite slab uranium areal density $\left(\mathrm{kg} / \mathrm{ft}^{2}\right)$ vs thickness (in.)

NUREG/CR-6504,

Vol. 2 


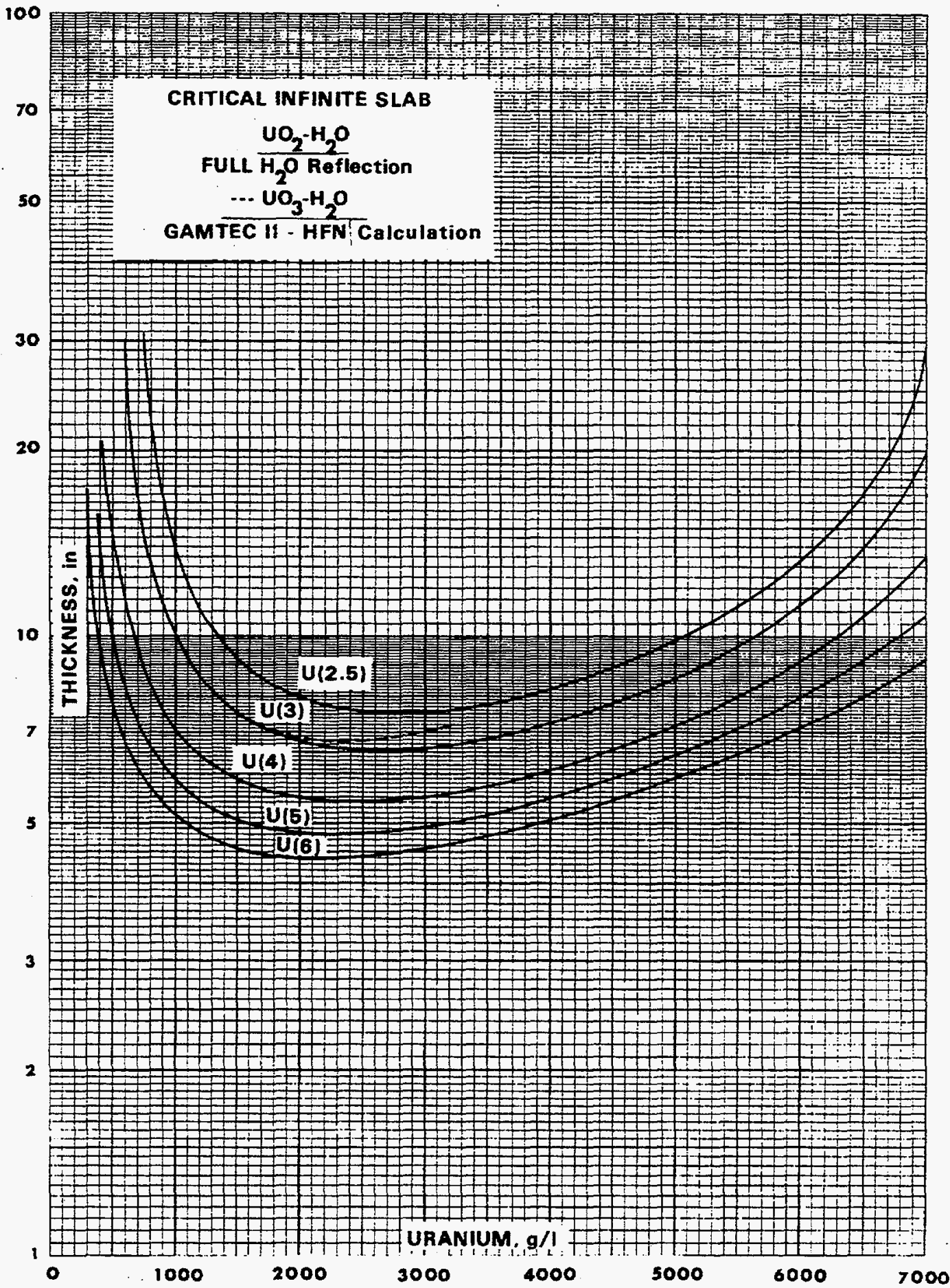

Figure 8 LEU UO $\mathrm{LO}_{2}-\mathrm{H}_{2} \mathrm{O}$ critical infinite slab thickness (in.) vs uranium density (g/L) 


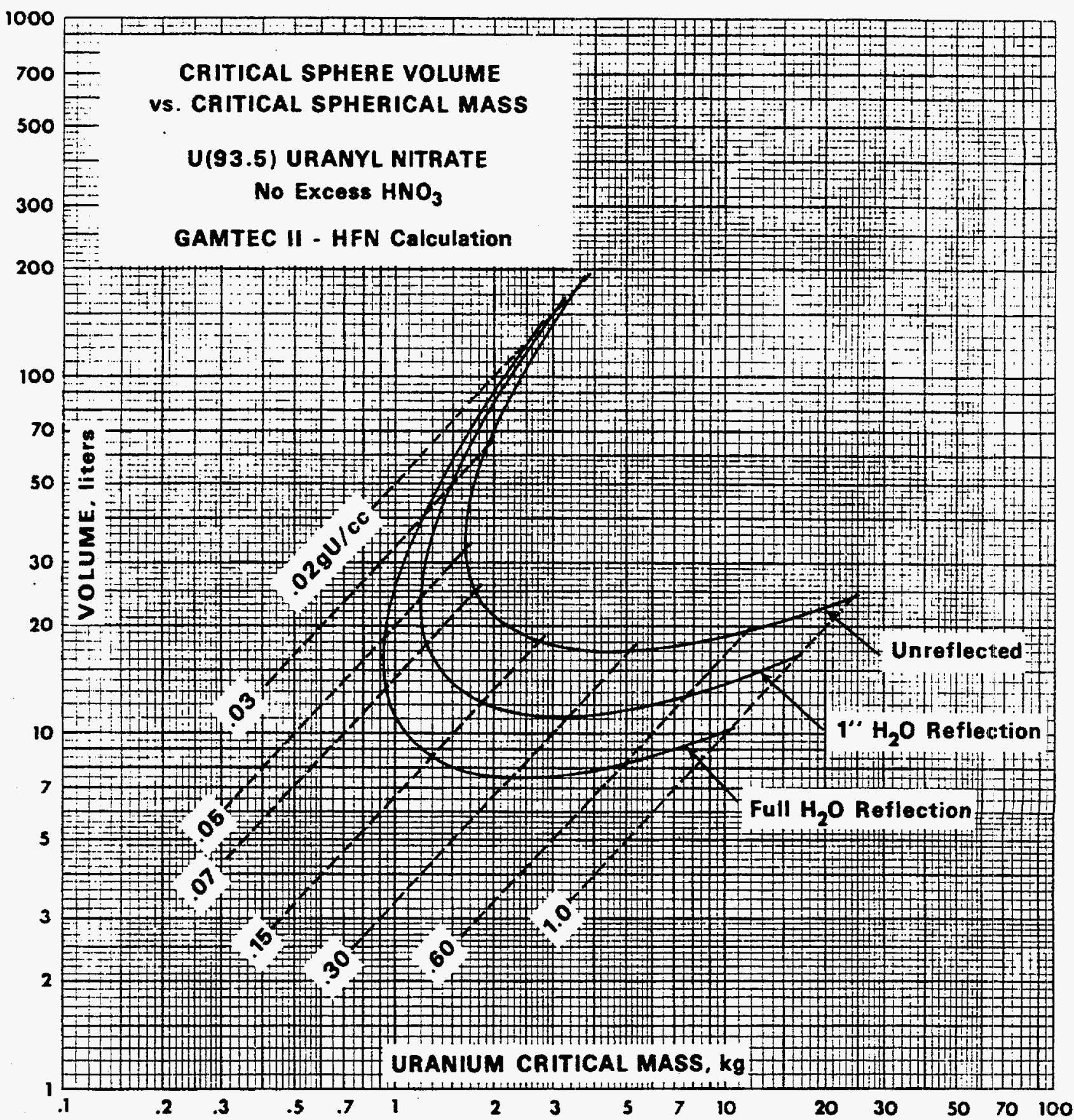

Figure $9 \mathrm{HEU} \mathrm{UO}_{2}\left(\mathrm{NO}_{3}\right)_{2}-\mathrm{H}_{2} \mathrm{O}$ critical sphere volume (L) vs uranium mass $(\mathrm{kg})$

NUREG/CR-6504,

Vol. 2 


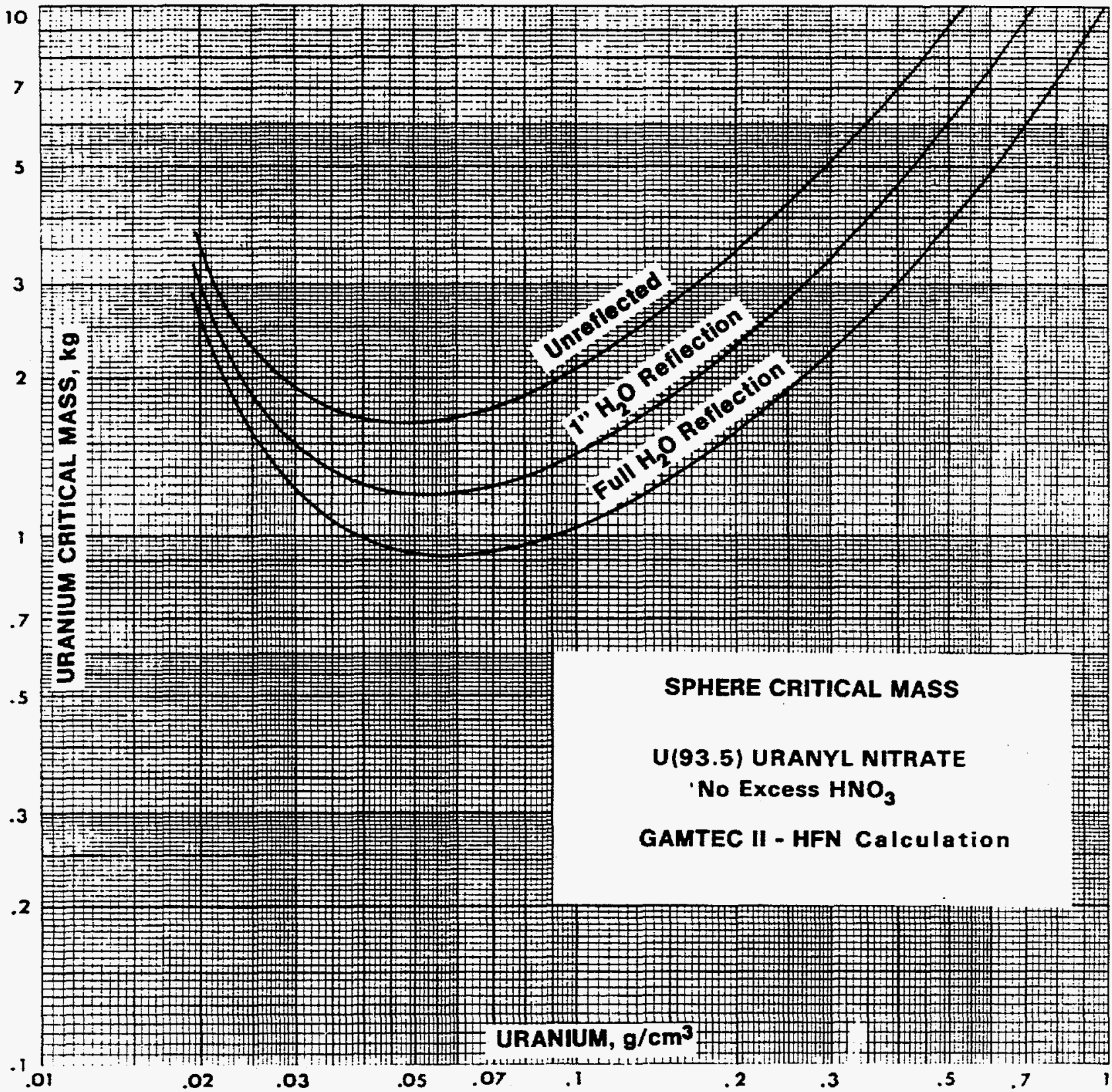

Figure 10 HEU UO $\mathrm{HO}_{2}\left(\mathrm{NO}_{3}\right)_{2}-\mathrm{H}_{2} \mathrm{O}$ critical sphere uranium mass $(\mathrm{kg})$ vs uranium density $\left(\mathrm{g} / \mathrm{cm}^{3}\right)$ 


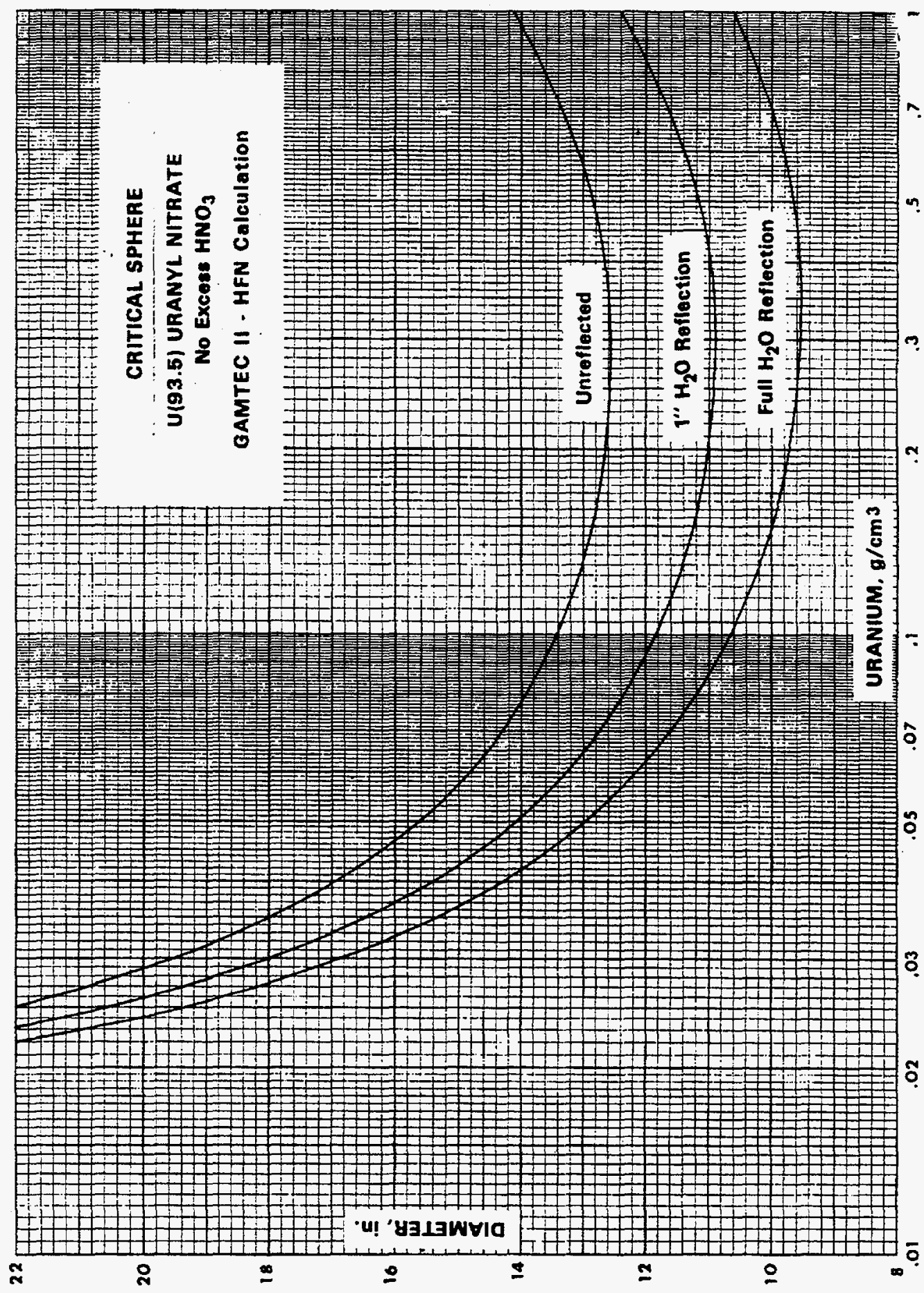

告

NUREG/CR-6504,

Vol. 2 


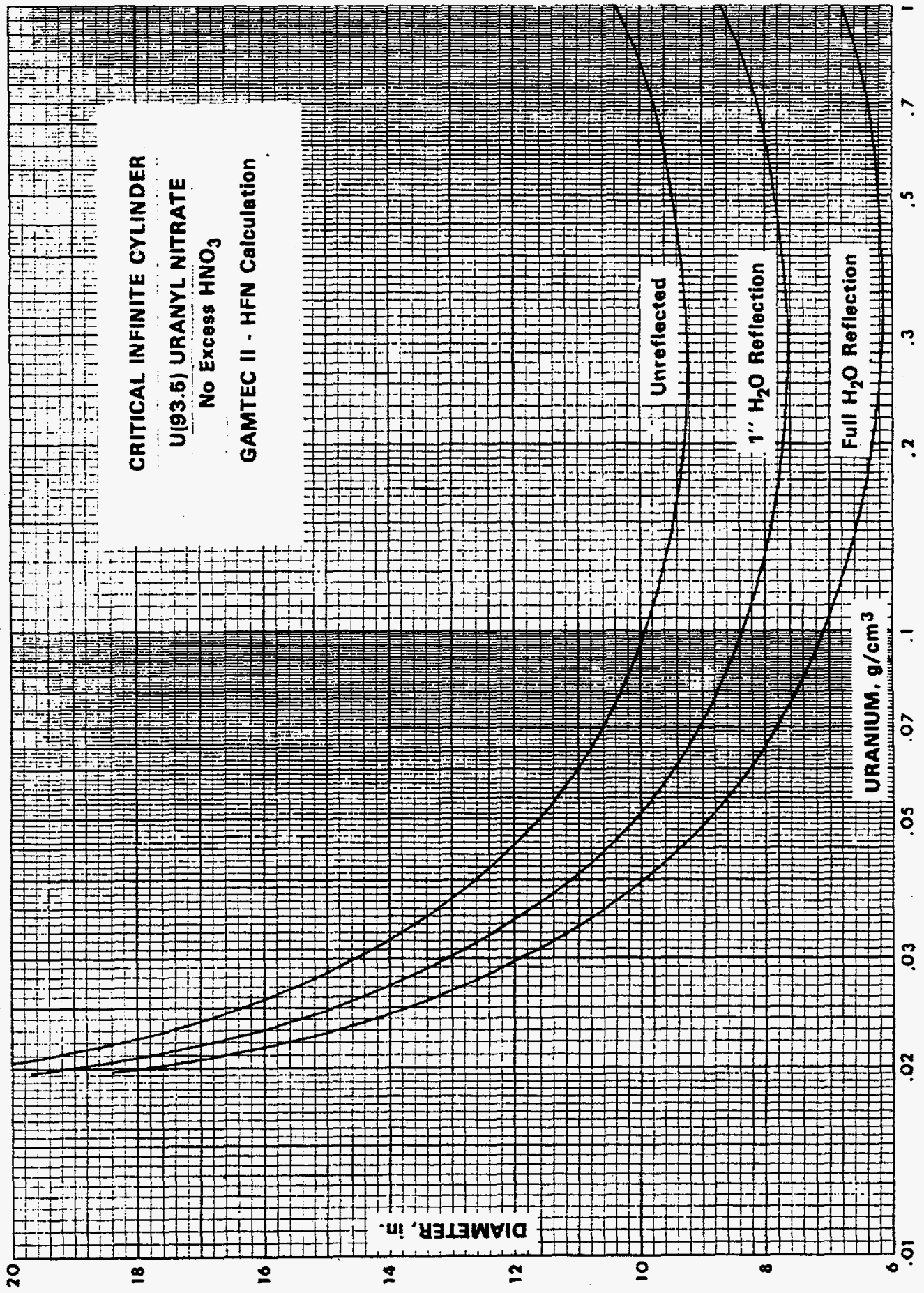




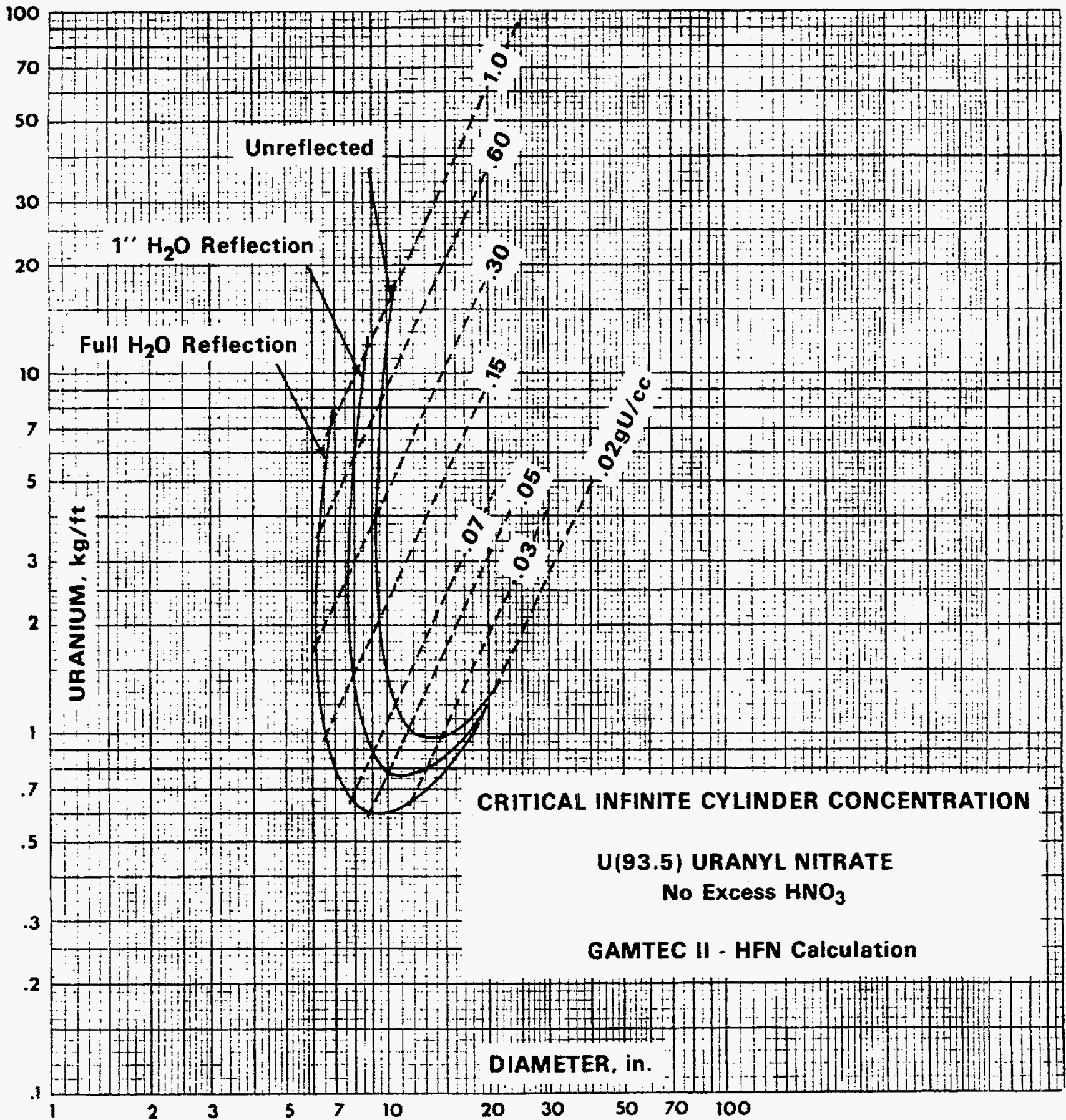

Figure $13 \mathrm{HEU} \mathrm{UO} \mathrm{HO}_{2}\left(\mathrm{NO}_{3}\right)_{2}-\mathrm{H}_{2} \mathrm{O}$ critical cylinder uranium linear density (kg/ft) vs diameter (in.)

NUREG/CR-6504,

Vol. 2 


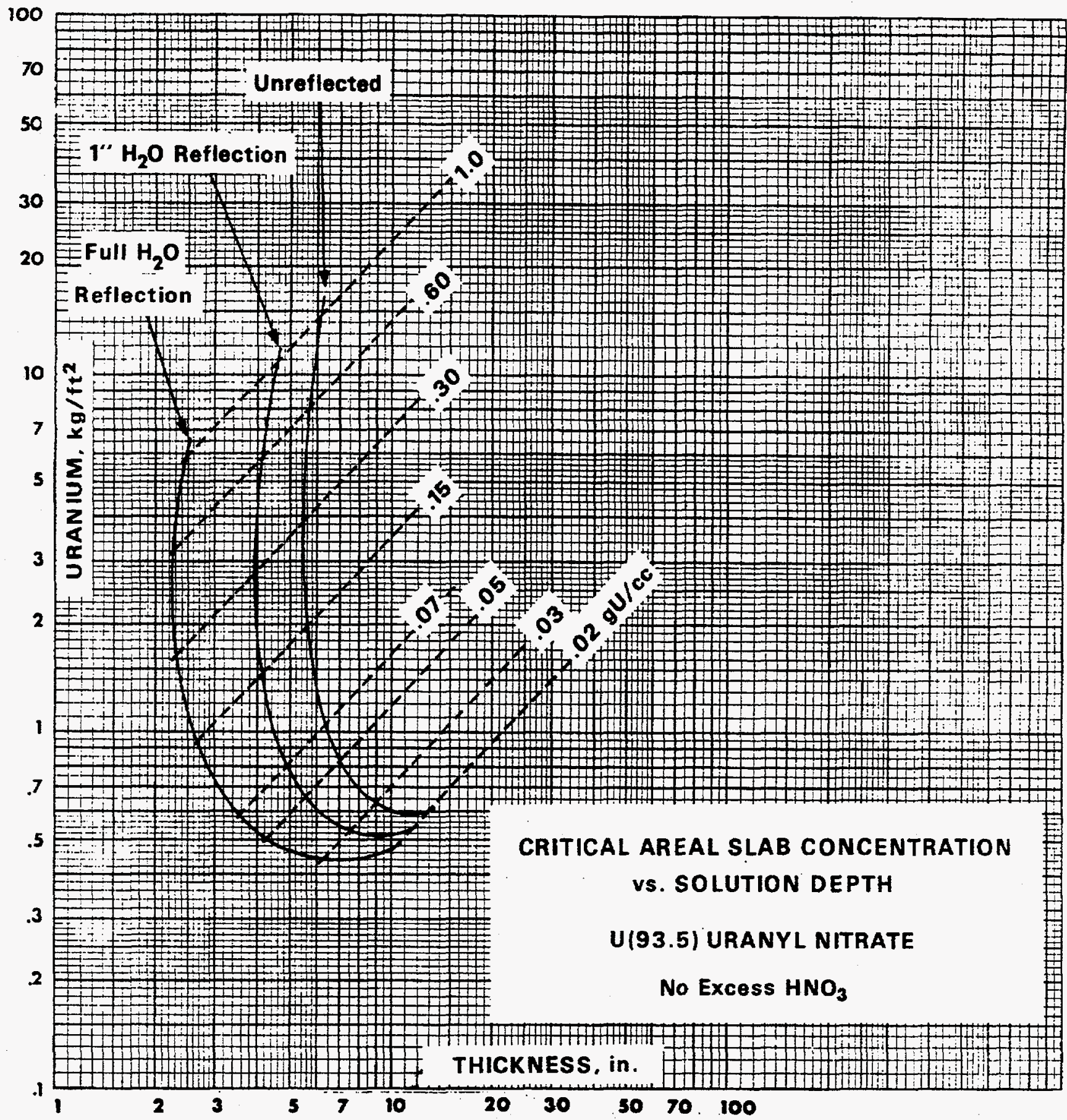

Figure 14 HEU UO $\mathrm{HO}_{2}\left(\mathrm{NO}_{3}\right)_{2}-\mathrm{H}_{2} \mathrm{O}$ critical slab uranium areal density $\left(\mathrm{kg} / \mathrm{ft}^{2}\right)$ vs thickness (in.) 


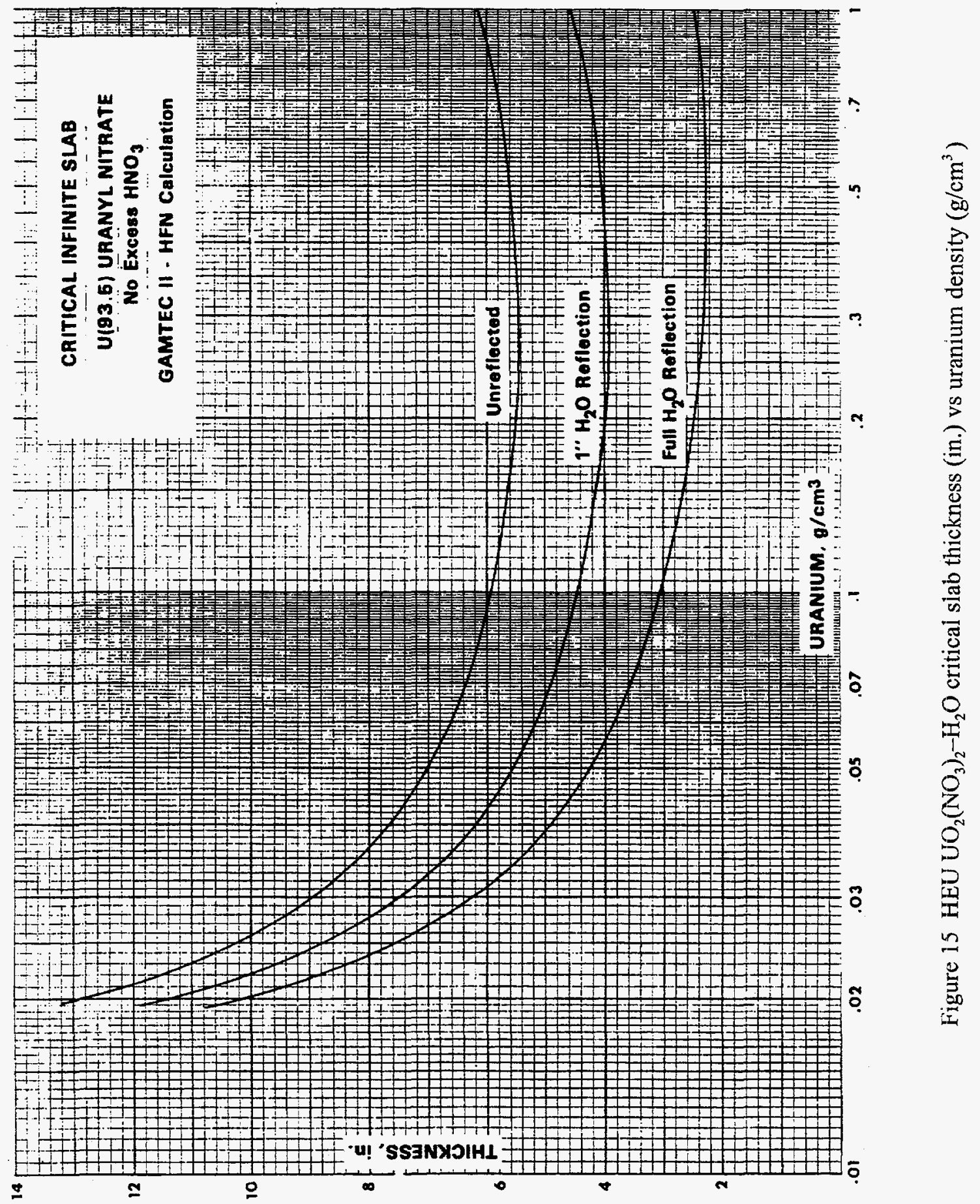

NUREG/CR-6504

Vol. 2 


\section{SUMMARY/CONCLUSIONS}

This slide rule is a functional update to the original slide rule published in limited form in the early 1970 s. The general format and features of the original slide rule are retained, in that the various curves include a promptdose-vs-distance relationship, a fission-product, gamma-dose-rate-vs-distance-and-time relationship, a totaldose-vs-time-and-distance relationship, and a 1-min total-dose-vs-time-and-distance relationship. The original slide rule consisted of only two system types - highly enriched uranium solutions and metal - and contained a number of approximations, namely an assumed inverse-square relationship of neutron and gamma-ray doses with distance. The newly updated slide rule contains information for the following five systems:

1. unreflected sphere of $4.95 \mathrm{wt} \%$ enriched aqueous uranyl fluoride, $\mathrm{U}(4.95) \mathrm{O}_{2} \mathrm{~F}_{2} \cdot \mathrm{H}_{2} \mathrm{O}$, solution having a hydrogen-to- ${ }^{235} \mathrm{U}$ ratio of 410 (solution density $=2.16 \mathrm{~g} / \mathrm{cm}^{3}$ ),

2. unreflected sphere of damp $5 \mathrm{wt} \%$ enriched uranium dioxide, $\mathrm{U}(5) \mathrm{O}_{2}$ having a hydrogen-to- ${ }^{235} \mathrm{U}$ ratio of 200 ,

3. unreflected sphere of $93.2 \mathrm{wt} \%$ enriched uranyl nitrate, $\mathrm{U}(93.2) \mathrm{O}_{2}\left(\mathrm{NO}_{3}\right)_{2} \cdot 6 \mathrm{H} 2 \mathrm{O}$, solution having a hydrogento ${ }^{235} \mathrm{U}$ atom ratio of 500 (solution density $=1.075 \mathrm{~g} / \mathrm{cm}^{3}$ ),

4. unreflected sphere of $93.2 \mathrm{wt} \%$ enriched uranium metal sphere (metal density $=18.85 \mathrm{~g} / \mathrm{cm}^{3}$ ), and

5. unreflected sphere of damp $93.2 \mathrm{wt} \%$ enriched uranium oxide, $\mathrm{U}_{3} \mathrm{O}_{8}$ plus water, having a hydrogen-to- ${ }^{235} \mathrm{U}$ atom ratio of 10 (uranium oxide density $=4.15 \mathrm{~g} / \mathrm{cm}^{3}$ ).

This update also includes not only the air/ground interface effects near the assumed accident, but out to $4000 \mathrm{ft}$ $(1219.2 \mathrm{~m})$ as well. The possibility of a shielded criticality accident in which skyshine radiation can be important is also treated, with the inclusion of a separate skyshine contribution as a function of distance from the accident. Also, results of first-pulse, fission-yield estimate evaluations are presented as functions of vertical or horizontal cylindrical critical volumes (based upon the degree of fissile material moderation expressed in terms of uranium density and cylinder dimension) and material addition rates. The first-pulse, fission-yield estimates may then be used for determining appropriate mitigating measures for protection of personnel as an uncontrolled system approaches criticality.

Though the presentation of dose and dose-rate information for less than $1 \mathrm{~min}$ (i.e., 1 to $60 \mathrm{~s}$ elapsed time) following the initial or prompt fission yield has no use for an emergency response, the information is useful for emergency preparedness in the training of personnel to respond quickly to a criticality accident alarm or in the estimation of radiation fields at the time of the accident, or very shortly thereafter. 


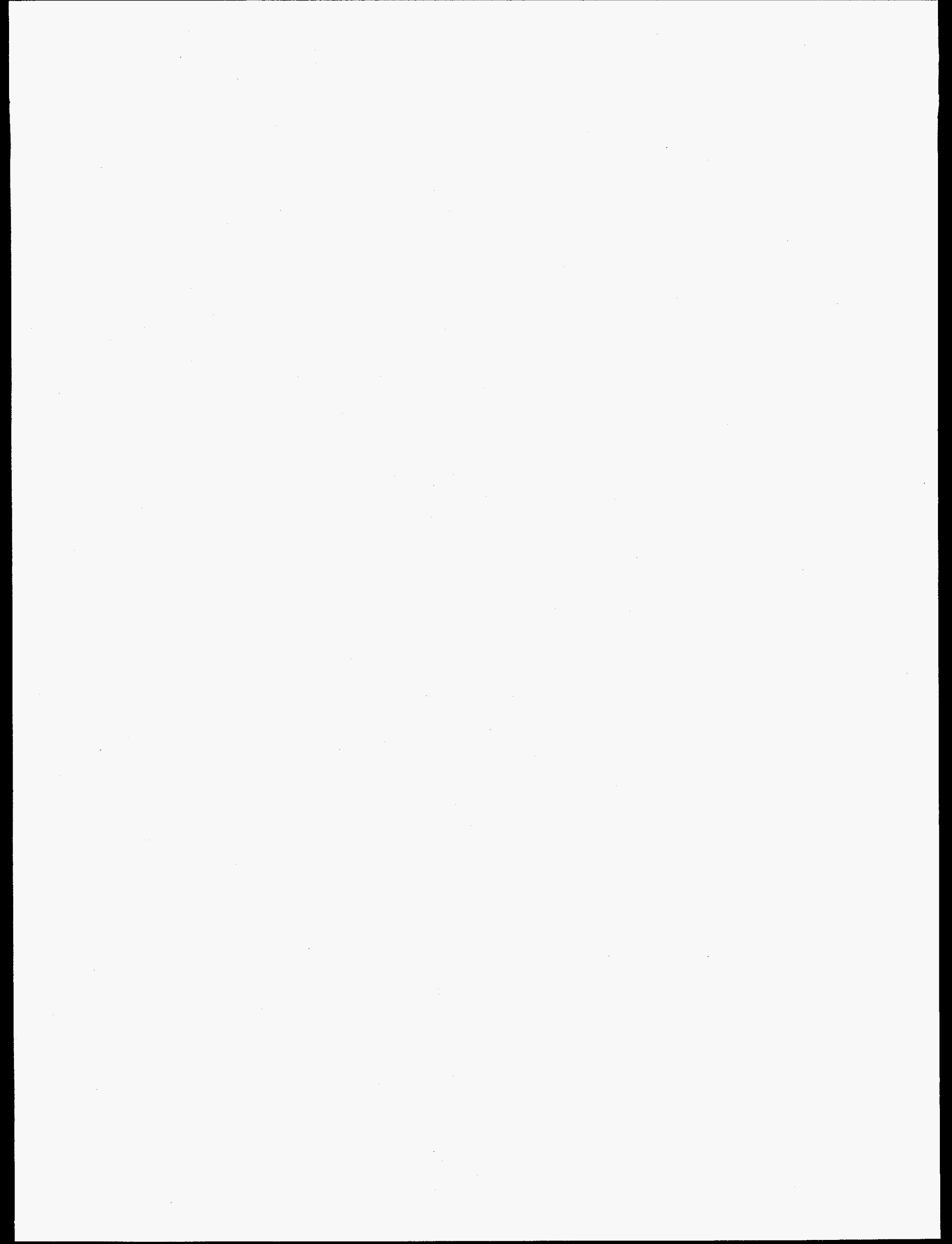




\section{REFERENCES}

1. C. M. Hopper, Slide Rule for Estimating Nuclear Criticality Information, Y-DD-145, Union Carbide Corp., Nucl. Div., Oak Ridge Natl. Lab., 1974.

2. R. D. Carter, G. R. Kiel, and K. R. Ridgway, Criticality Handbook, ARH-600, Vol. II, Atlantic Richfield Hanford Co., Richland, Wash., May 23, 1969.

3. F. Barbry, "Model to Estimate the Maximum Fission Yield in Accidental Solution Excursions," Trans. Am. Nucl. Soc. 55, $412-414$ (1987). 


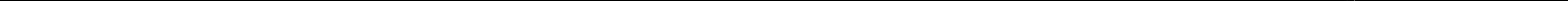




\section{APPENDIX}

\section{CONTENTS}

Slide 1 Solution of $\mathrm{U}(93.2) \mathrm{O}_{2}\left(\mathrm{NO}_{3}\right)_{2} @ \mathrm{H}^{235} \mathrm{U}=500$

Slide $2 \mathrm{U}(93.2)$ metal

Slide 3 Damp U(93.2) $)_{3} @ \mathrm{O}_{8}{ }^{235} \mathrm{U}=10$

Slide 4 Damp U(4.95) $\mathrm{O}_{2} \mathrm{~F}_{2} @ \mathrm{H} /{ }^{235} \mathrm{U}=410$

Slide 5 Damp U(5) $\mathrm{O}_{2} @ \mathrm{H}^{2}{ }^{235} \mathrm{U}=200$

Slide 6 First-pulse, fission-yield estimates for vertical and horizontal cylinders of HEU and LEU solutions CONVERSION FACTORS AND EQUALITIES 


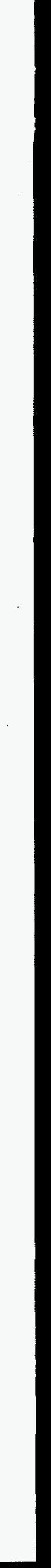




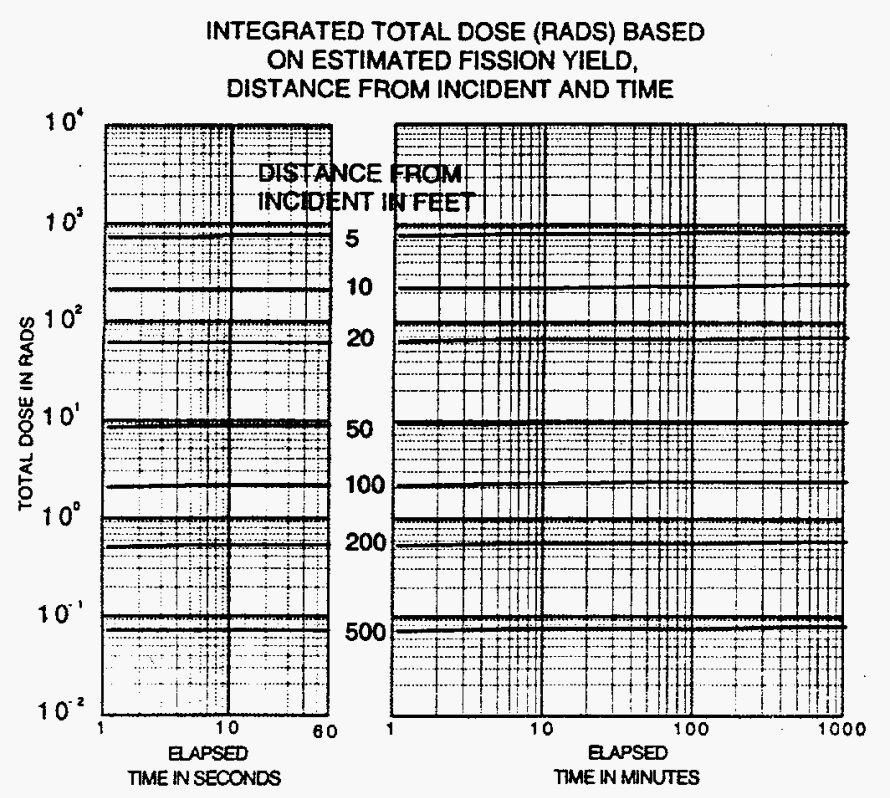

ESTIMATED PROMPT DOSES

BASED ON TOTAL FISSION YIELD,

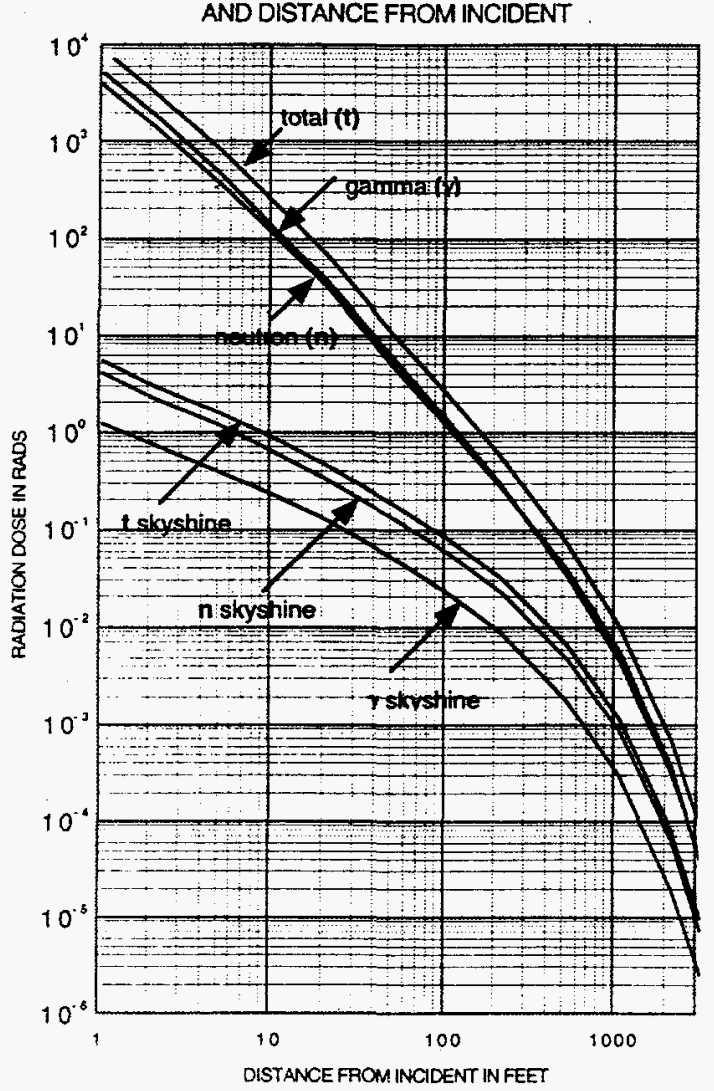

ACCUMULATED

ONE MINUTE DOSE (RADS) BASED ON

ESTIMATED FISSION YIELD, DISTANCE FROM

INCIDENT AND TIME OF ENTRY AFTER INCIDENT
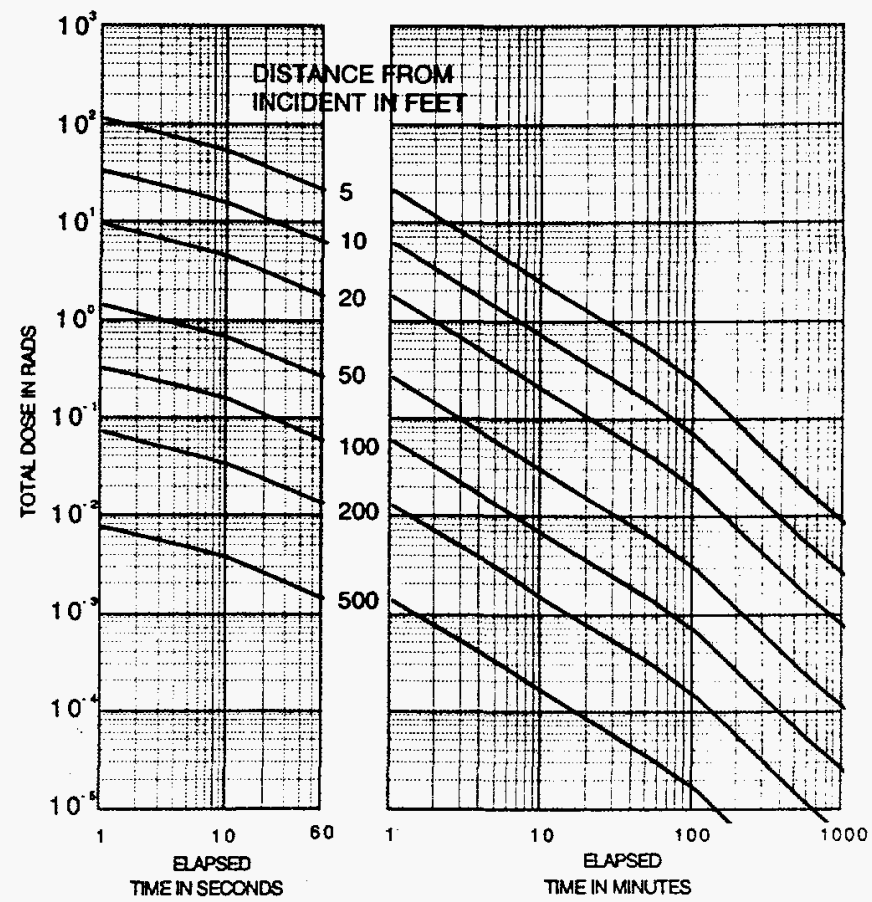

ESTIMATED FISSION YIELD

BASED ON DISTANT GAMMA
DOSE RATE AND ELAPSED TIME
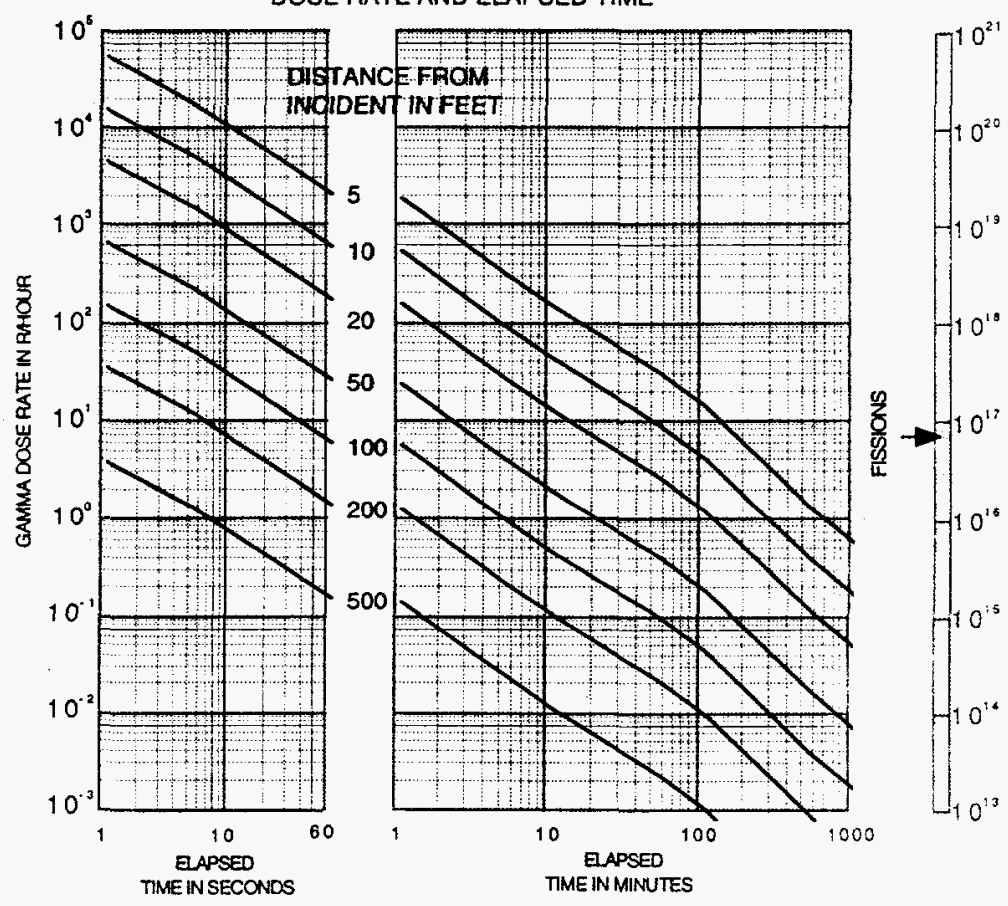

Slide 1 Solution of $\mathrm{U}(93.2) \mathrm{O}_{2}\left(\mathrm{NO}_{3}\right)_{2} @ \mathrm{H} /{ }^{235} \mathrm{U}=500$ 
INTEGRATED TOTAL DOSE (RADS) BASED ON ESTIMATED FISSION YIELD

DISTANCE FROM INCIDENT AND TIME

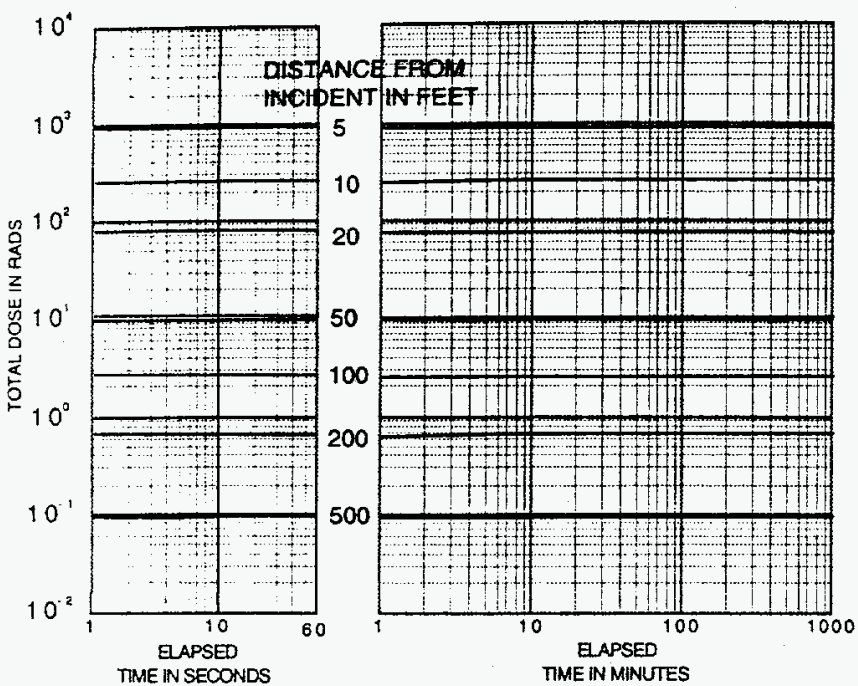

ESTIMATED PROMPT DOSES

BASED ON TOTAL FISSION YIELD,

AND DISTANCE FROM INCIDENT

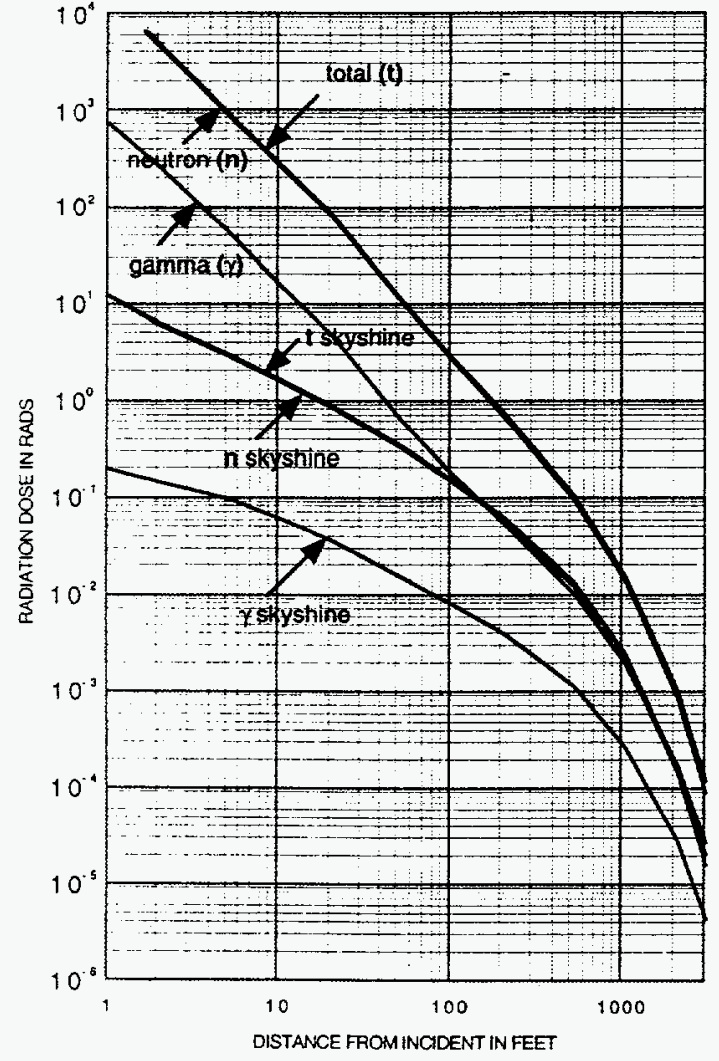

ACCUMULATED

ONE MINUTE DOSE (RADS) BASED ON

ESTIMATED FISSION YIELD, DISTANCE FROM

INCIDENT AND TIME OF ENTRY AFTER INCIDENT
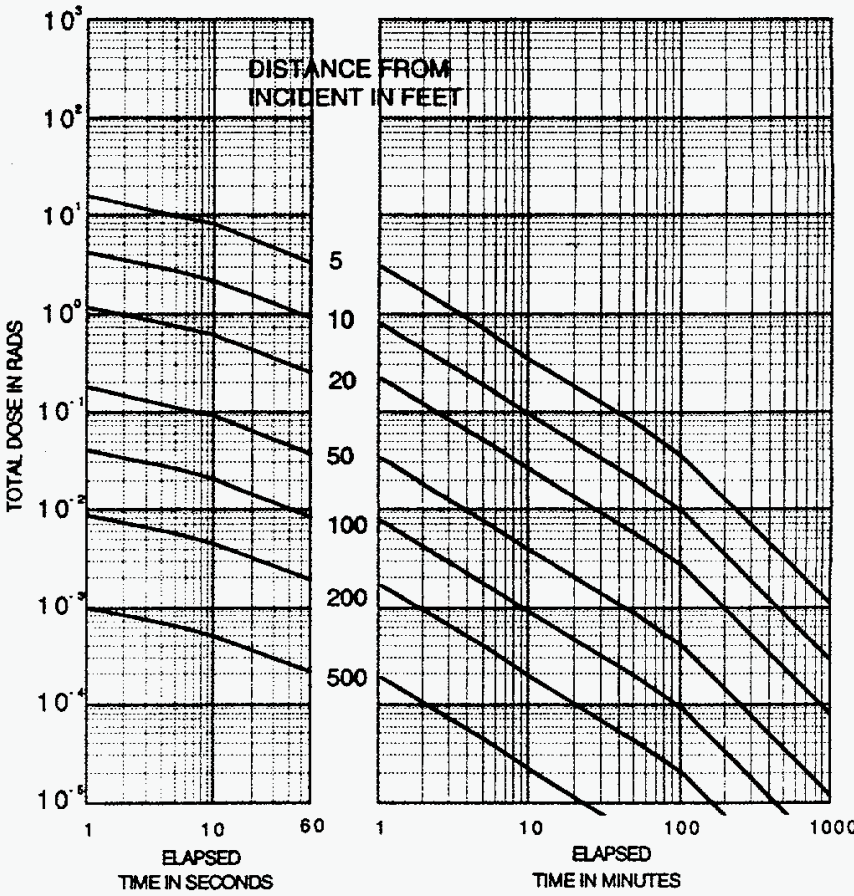

ESTIMATED FISSION YIELD

BASED ON DISTANT GAMMA

DOSE RATE AND ELAPSED TIME

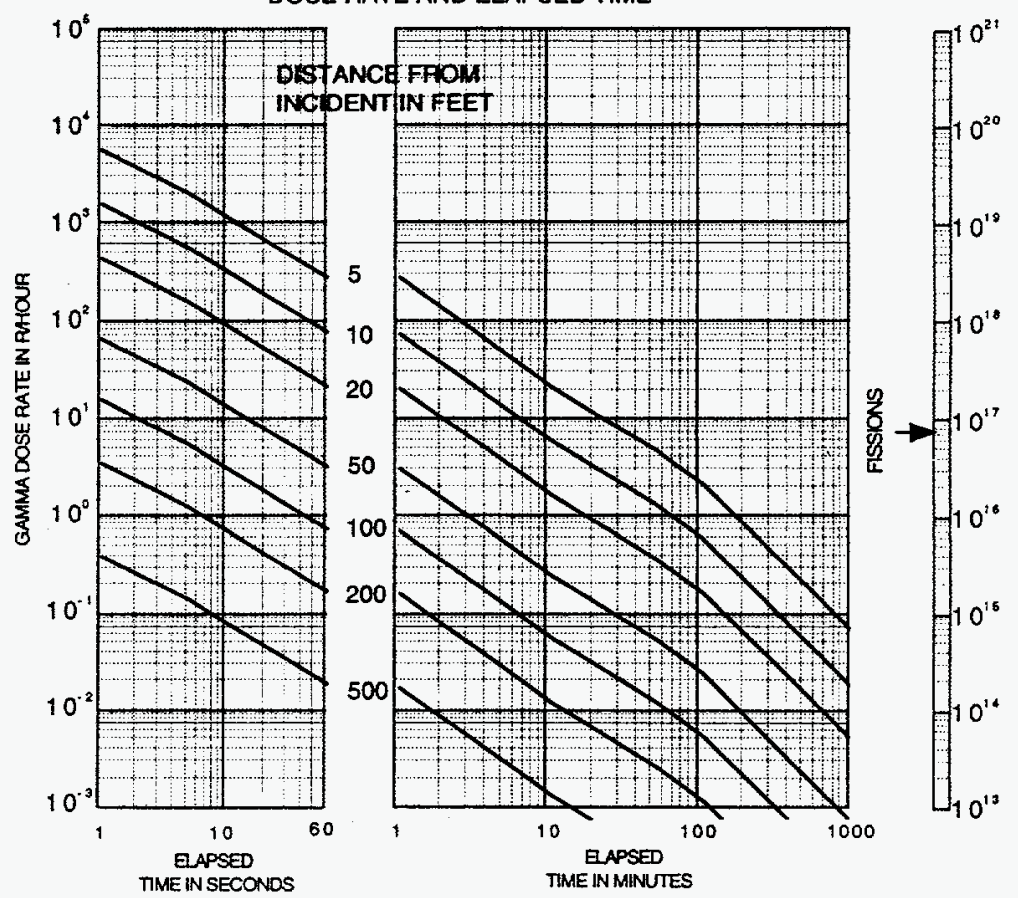

Slide 2 U(93.2) metal 


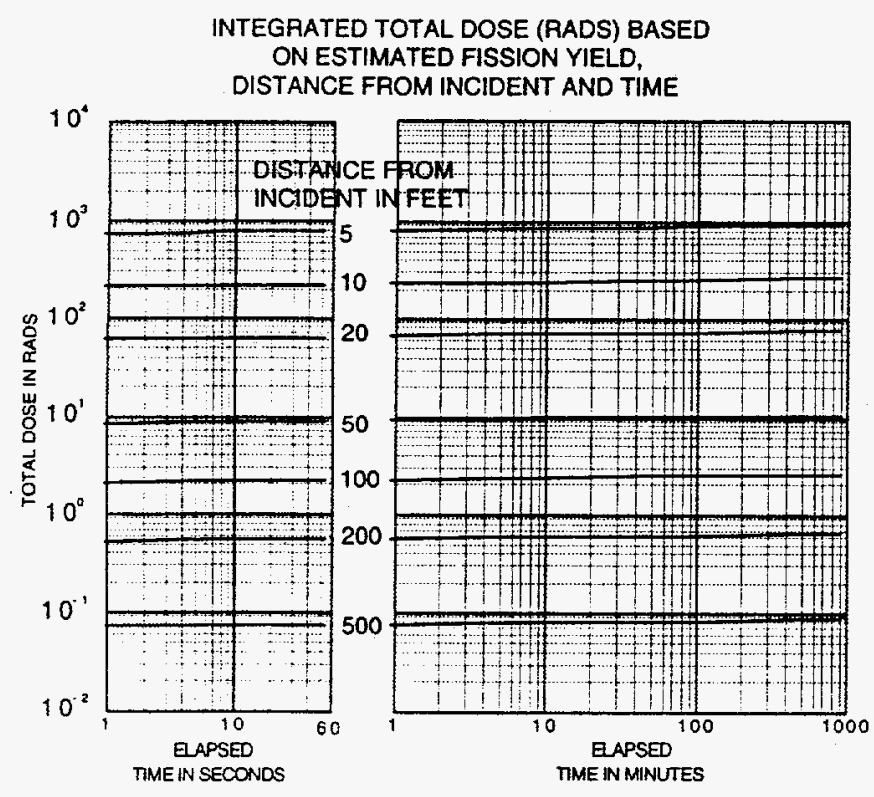

ESTIMATED PROMPT DOSES

BASED ON TOTAL FISSION YIELD,

AND DISTANCE FROM INCIDENT

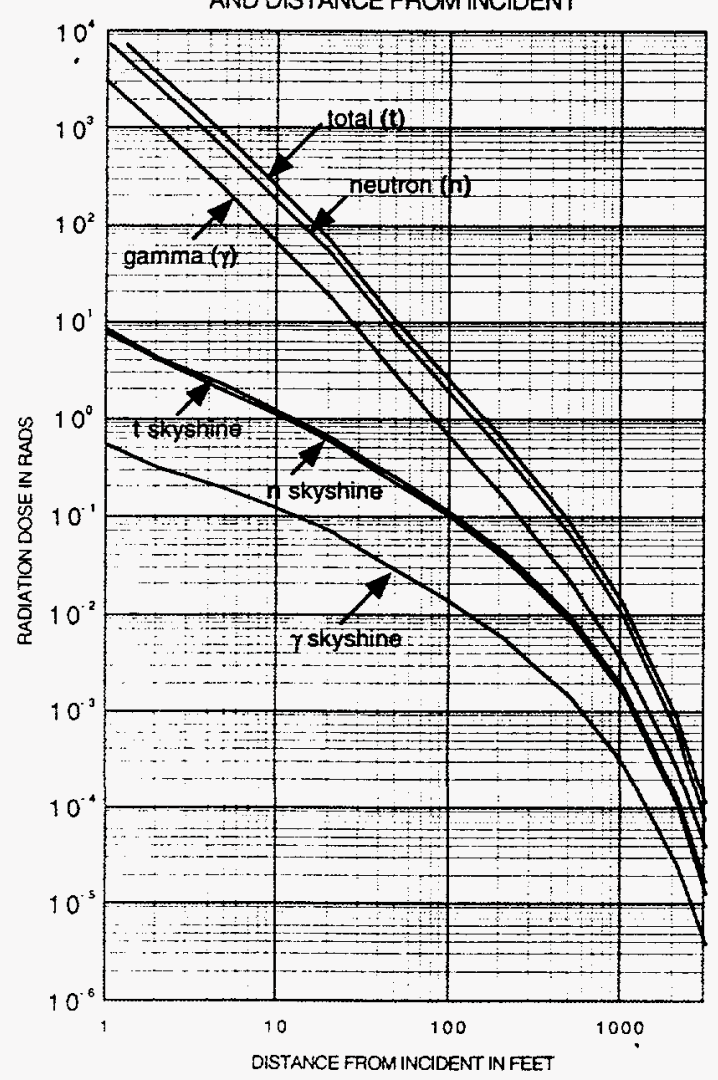

ACCUMULATED

ONE MINUTE DOSE (RADS) BASED ON

ESTIMATED FISSION YIELD DISTANCE FROM

INCIDENT AND TIME OF ENTRY AFTER INCIDENT
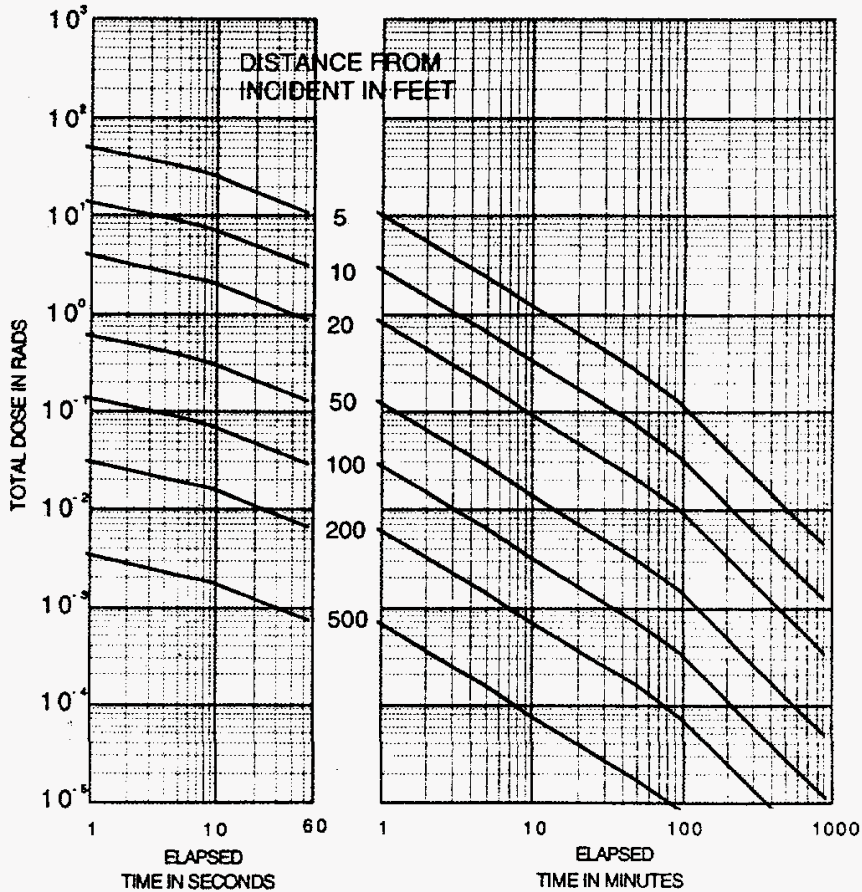

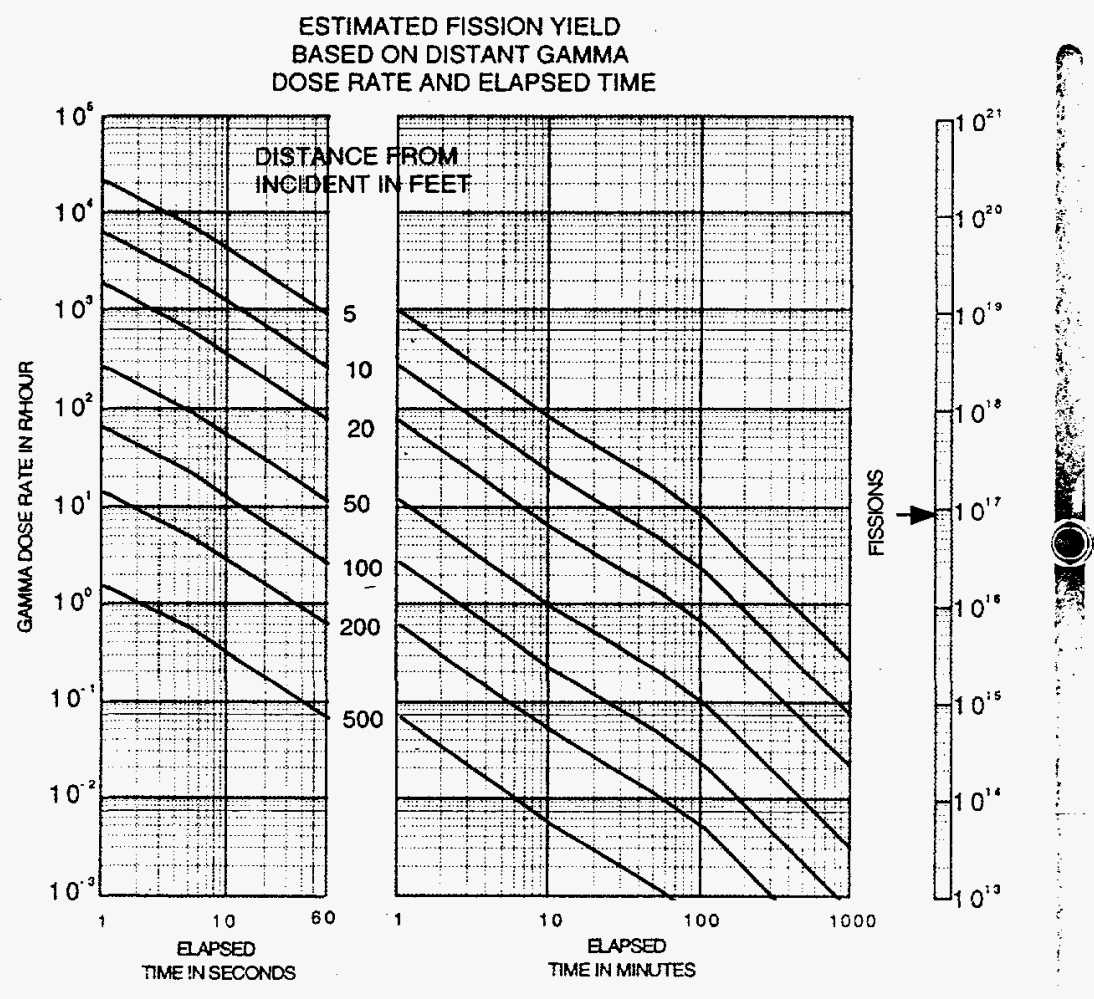

Slide 3 Damp $\mathrm{U}(93.2)_{3} \mathrm{O}_{8} @ \mathrm{H} /^{235} \mathrm{U} \approx 10$ 
INTEGRATED TOTAL DOSE (RADS) BASED ON ESTIMATED FISSION YIELD,

DISTANCE FROM INCIOENT AND TIME

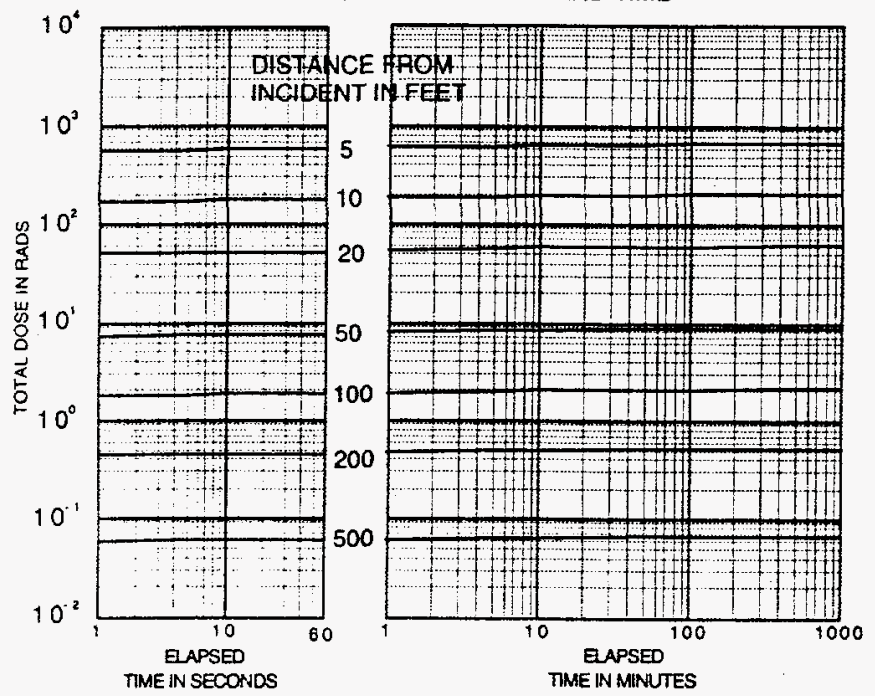

ESTIMATED PROMPT DOSES

BASED ON TOTAL FISSION YIELD,

AND DISTANCE FROM INCIDENT

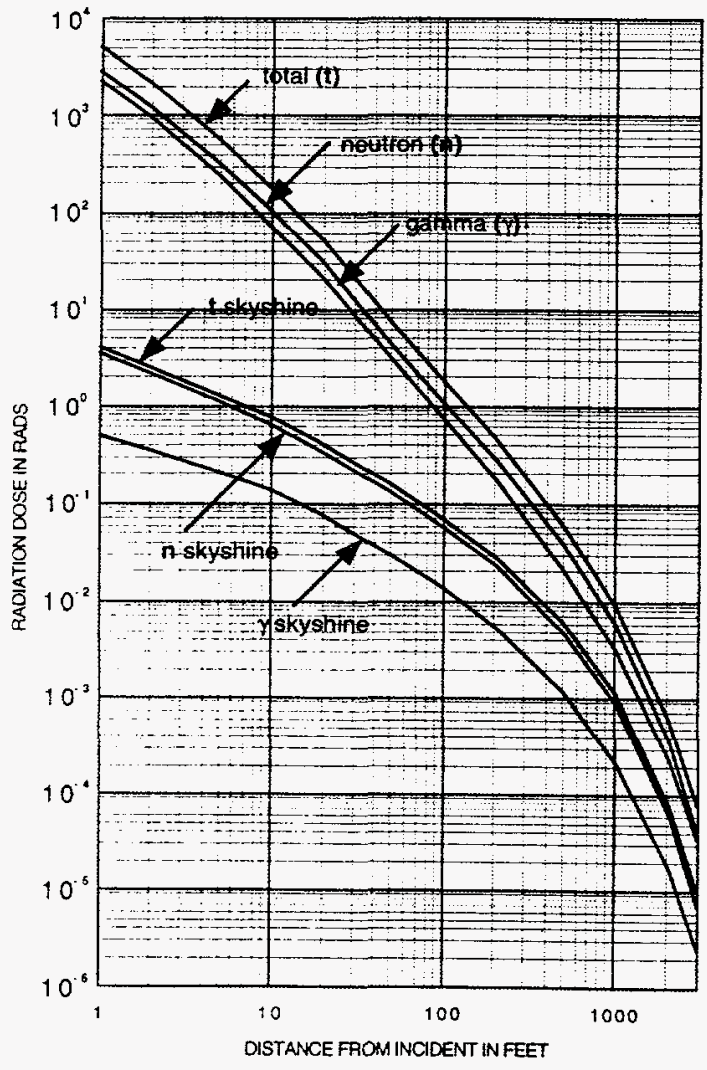

Slide 4 Damp $\mathrm{U}(4.95) \mathrm{O}_{2} \mathrm{~F}_{2} @ \mathrm{H} /{ }^{235} \mathrm{U} \approx 410$
ACCUMULATED

ONE MINUTE DOSE (RADS) BASED ON ESTIMATED FISSION YIELD, DISTANCE FROM

INCIDENT AND TIME OF ENTRY AFTER INCIDENT

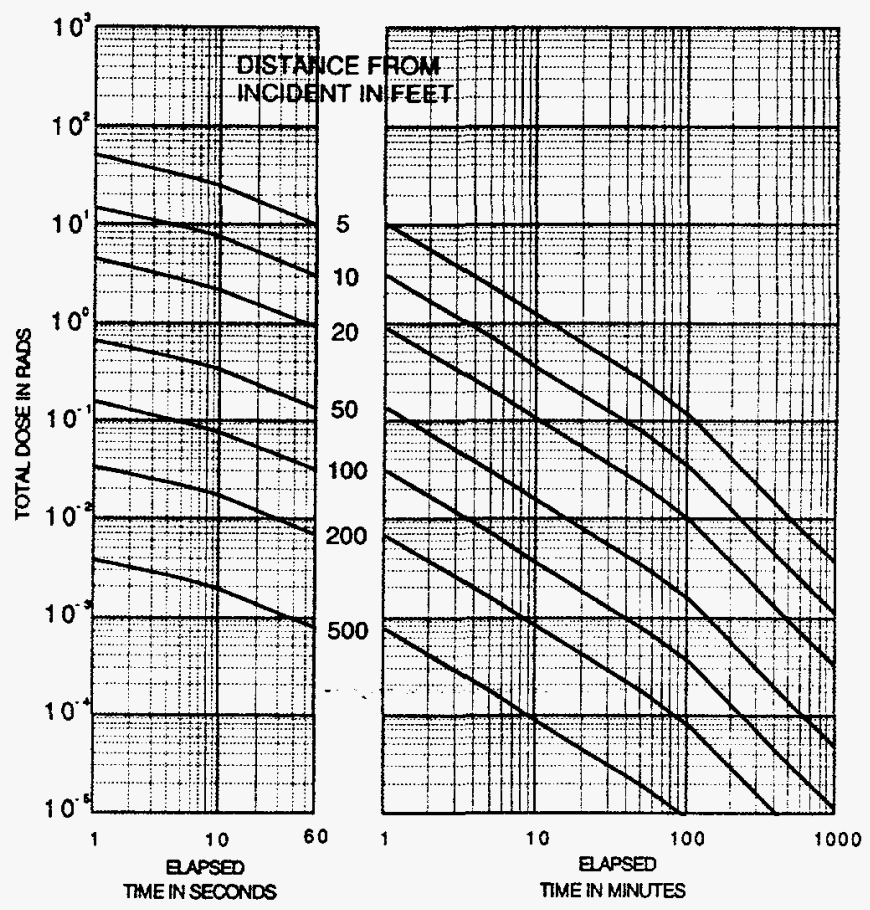

ESTIMATED FISSION YIELD

BASED ON DISTANT GAMMA DOSE RATE AND ELAPSED TIME
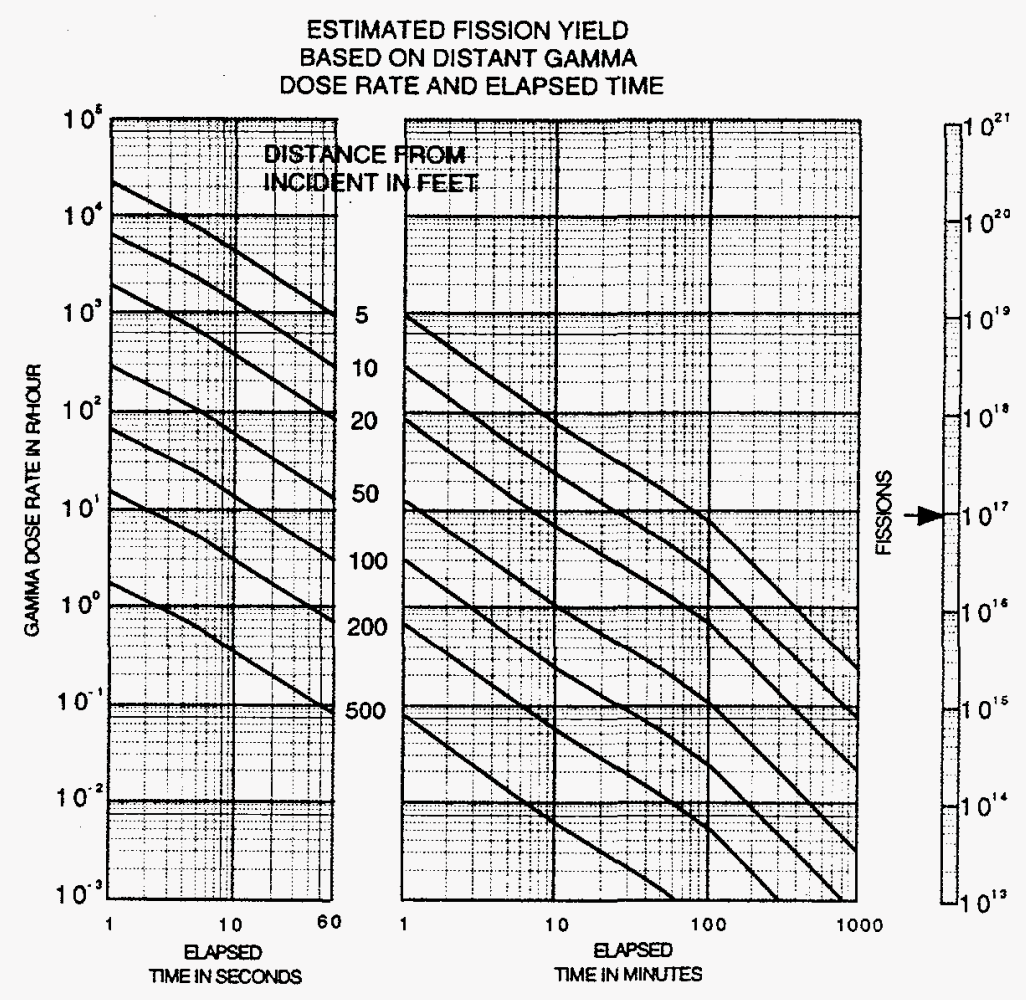

t 


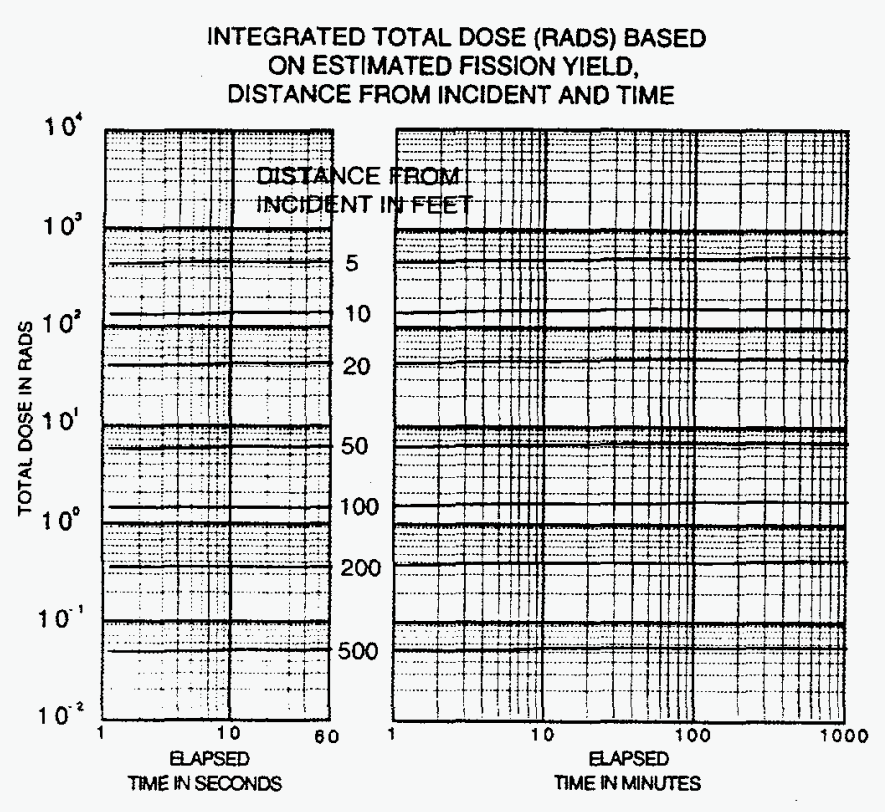

ESTIMATED PROMPT DOSES

BASED ON TOTAL FISSION YIELD, AND DISTANCE FROM INCIDENT

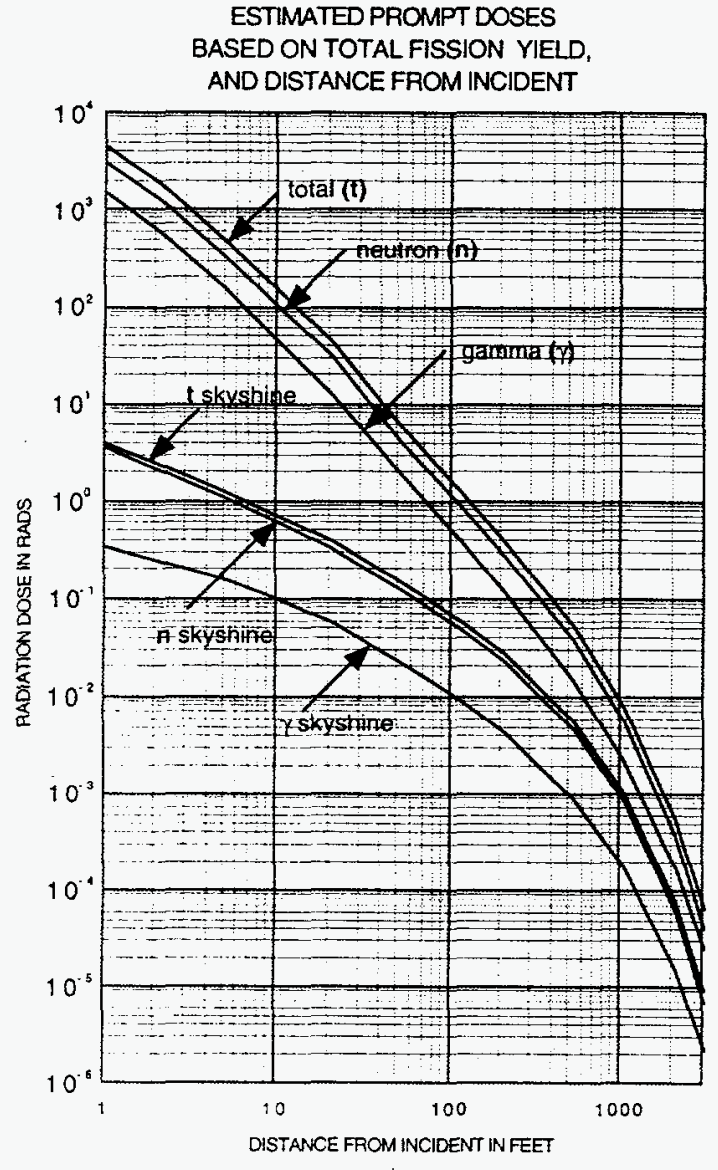

ACCUMULATED

ONE MINUTE DOSE (RADS) BASED ON ESTIMATED FISSION YIELD, DISTANCE FROM INCIDENT AND TIME OF ENTRY AFTER INCIDENT
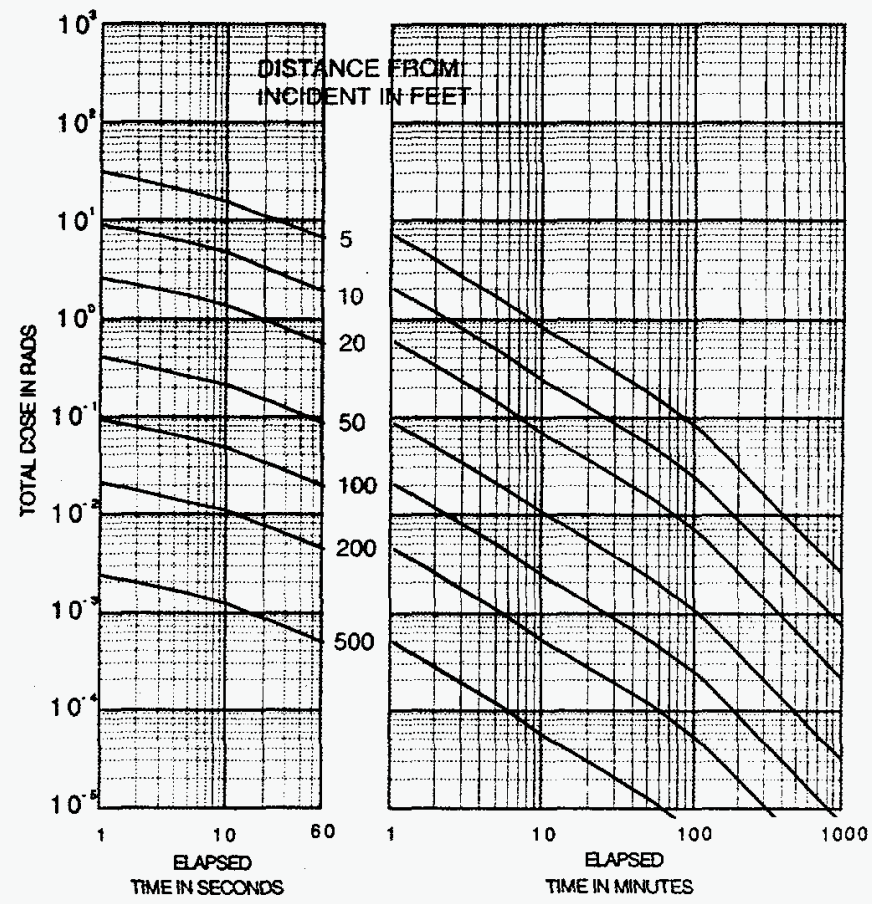
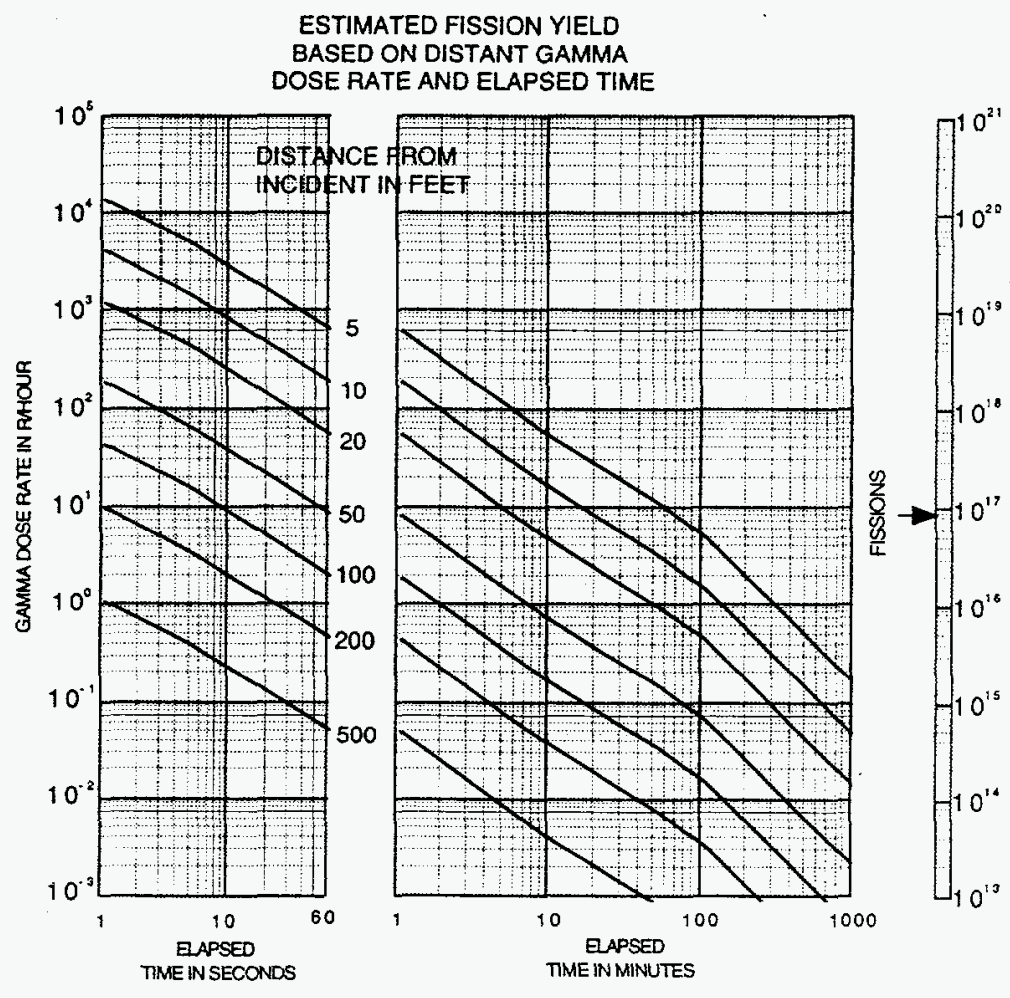

Slide 5 Damp $U(5) \mathrm{O}_{2} @ \mathrm{H} /{ }^{235} \mathrm{U} \approx 200$ 

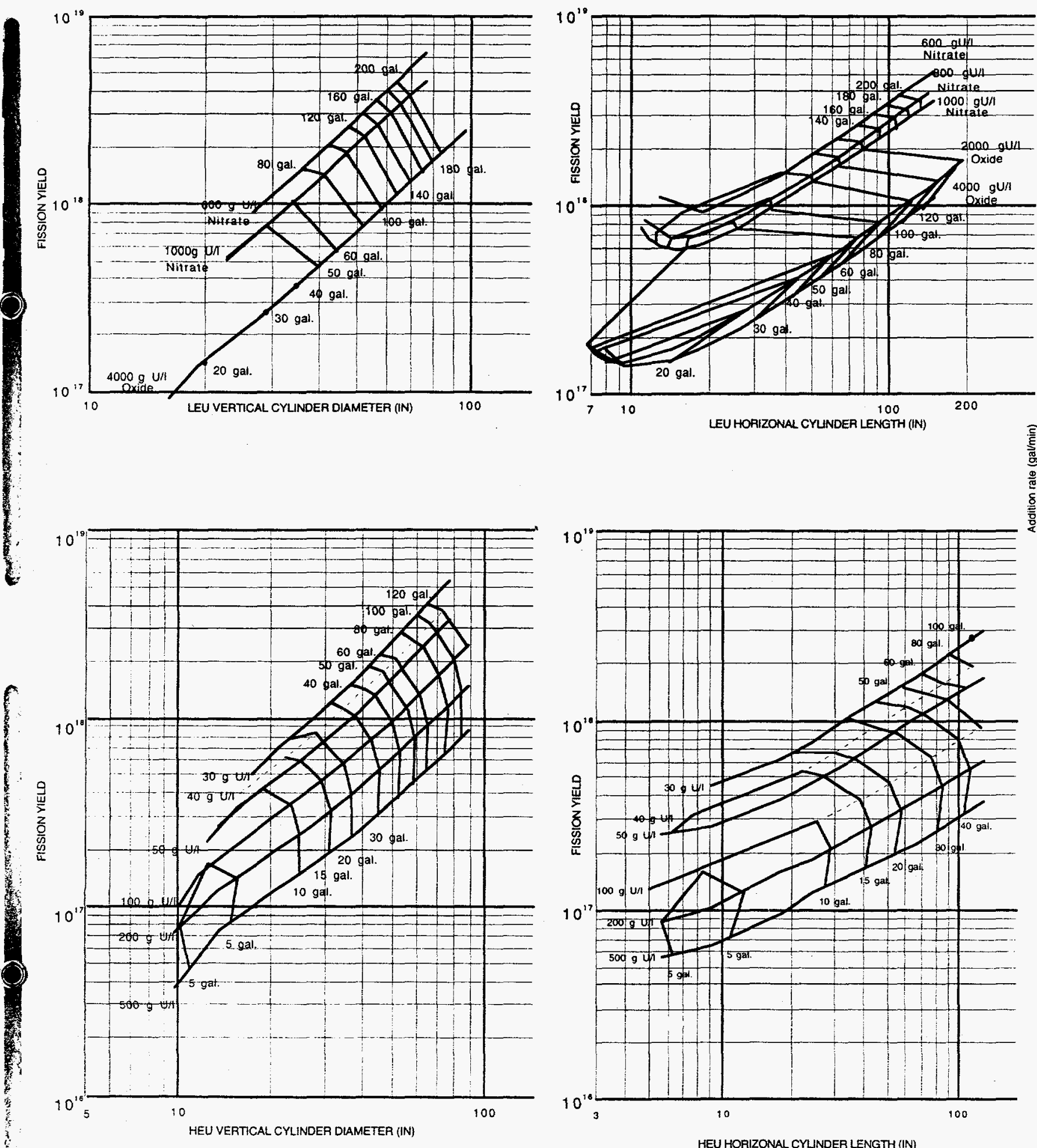

HEU HOPIZONAL CYUNDER LENGTH (IN)

Slide 6 First Pulse Fission Yield Estimates for Vertical and Horizontal Cylinders of HEU and LEU Solutions 


\section{CONVERSION FACTORS AND EQUALITIES}

It requires approximately $10^{17}$ fissions to evaporate $1 \mathrm{~L}$ of water that was originally at room temperature.

It requires approximately $3.8 \times 10^{17}$ fissions to evaporate 1 gal of water that was originally at room temperature.

$3.12 \times 10^{10}$ fissions per seconds $(\mathrm{s})=1$ watt $(\mathrm{w})$

$1.123 \times 10^{14}$ fissions $=1 \mathrm{w}-\mathrm{hr}$

$1 \mathrm{gal}=3.785 \mathrm{~L}$

$1 \operatorname{liter}(\mathrm{L})=0.264 \mathrm{gal}$

1 liter $(\mathrm{L}) / \mathrm{min}=0.264 \mathrm{gal} / \mathrm{min}$

1 cubic foot $\left(\mathrm{ft}^{3}\right)=7.481 \mathrm{gal}$

$1 \mathrm{~cm}=0.394 \mathrm{in}$.

The total fission yield ${ }^{3}$ of a continuing aqueous solution criticality may be estimated by:

$$
\begin{aligned}
\text { Total Fissions } & =\frac{[(\text { Solution volume, gal }) \times(\text { Duration of criticality, min })]}{1.563 \times 10^{-17}+\left[1.686 \times 10^{-17} \times(\text { Duration of criticality, min })\right]} \\
& =\frac{[(\quad \text { gal }) \times(\longrightarrow \text { min })] \text { fissions }}{1.563 \times 10^{-17}+\left[1.686 \times 10^{-17} \times\left(\mathrm{min}^{-17}\right]\right.}=\longrightarrow \text { fissions }
\end{aligned}
$$

or

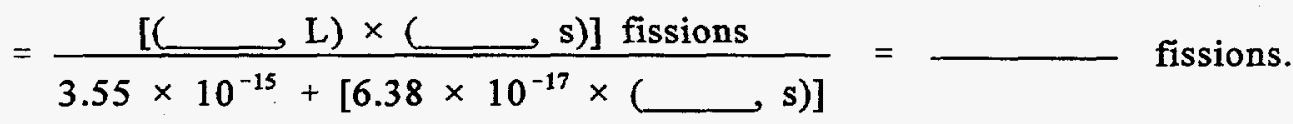

Shielding dose reduction factors may be determined from the following relationships:

Steel Dose Reduction Factor:

Concrete Dose Reduction Factor:

Water Dose Reduction Factor:

Solution of $\mathrm{U}(93.2) \mathrm{O}_{2}\left(\mathrm{NO}_{3}\right)_{2} @ \mathrm{H}^{235} \mathrm{U}=500$

2. U(93.2) metal

3. Damp U(93.2) $)_{3} \mathrm{O}_{8} @ \mathrm{H}^{235} \mathrm{U}=10$

4. Damp U(4.95) $\mathrm{O}_{2} \mathrm{~F}_{2} @ \mathrm{H} /{ }^{235} \mathrm{U}=410$

5. Damp U(5)O $\mathrm{O}_{2} @ \mathrm{H}^{235} \mathrm{U}=200$ neutrons, $\mathrm{n}=\mathrm{e}^{-0.256 \times \text { steel thickness in inches }}$ gammas, $\gamma=\mathrm{e}^{-0.386 \times \text { steel thickness in inches }}$

neutrons, $\mathrm{n}=\mathrm{e}^{-0.240 \times \text { concrete thickness in inches }}$ gammas, $\gamma=\mathrm{e}^{-0.147 \times \text { concrete thickness in inches }}$

neutrons, $n=\mathrm{e}^{-0.277 \times \text { water thickness in inches }}$ gammas, $\gamma=\mathrm{e}^{-0.092 \times \text { water thickness in inches }}$ 
1. REPORT NUMBER

2. TITLE AND SUBTITLE

An Updated Nuclear Criticality Slide Rule

Functional Slide Rule

NUREG/CR-6504, Vol. 2

ORNLTM-13322N2

5. AUTHOR(S)
C.M. Hopper, B.L. Broadhead

\begin{tabular}{l|r} 
D. DATE REPORT PUBLISHED \\
MONTH & YEAR \\
April & 1998 \\
\hline
\end{tabular}

4. FIN OR GRANT NUMBER

W6303

6. TYPE OF REPORT

Technical

7. PERIOD COVERED (inciusive Dales)

8. PERFORMING ORGANIZATION - NAME AND ADDRESS (If NRC, provide Division, Office or Region, U.S. Nuclear Regulatony Commission, and mailing address; if contractor, provide name and mailing address.)

Oak Ridge National Laboratory

Oak Ridge, TN $37831-6370$

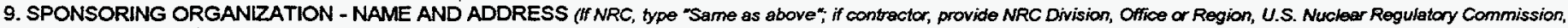
and mailing address.

Division of Regulatory Applications

Office of Nuclear Regulatory Research

U.S. Nuclear Regulatory Commission

Washington, DC 20555-0001

10. SUPPLEMENTARY NOTES

M.L. Thomas, NRC Project Manager

11. ABSTRACT (200 words or less)

This Volume 2 contains the functional version of the updated nuclear criticality slide rule (more accurately, sliding graphs) that is referenced in An Updated Nuclear Criticality Slide rule: Technical Basis, NUREG/CR-6504, Vol. 1(ORNLTM-13322N1). This functional slide rule provides a readily usable "in-hand" method for estimating pertinent nuclear criticality accident information from sliding graphs, thereby permitting (1) the rapid estimation of pertinent criticality accident information without laborious or sophisticated calculations in a nuclear criticality emergency situation, (2) the appraisal of potential fission yields and external personnel radiation exposures for facility safety analyses, and (3) a technical basis for emergency preparedness and training program at nonreactor nuclear facilities. The slide rule permits the estimation of neutron and gamma dose rates and integrated doses based upon estimated fission yields, distance from the fission source, and time-after criticality accidents for five different critical systems. Another sliding graph permits the estimation of critical solution fission yields based upon fissile material concentration, critical vessel geometry, and solution addition rate. Another graph provides neutron and gamma dose-reduction factors for water, steel, and concrete. Graphs from historic documents are provided as references for estimating critical parameters of various fissile material systems. Conversion factors for various English and metric units are provided for quick reference.

12. KEY WORDS/DESCRIPTORS (List words or phrases that wifl assist researchers in locating the report.)

emergency planning, emergency response, nuclear criitcality accident, slide rule, fission yields, shielding, radiation protection

\begin{tabular}{|c|}
\hline $\begin{array}{c}\text { 13. AVAILABILITY STATEMENT } \\
\text { unlimited }\end{array}$ \\
\hline 14. SECURITY CLASSIFICATION \\
\hline $\begin{array}{l}\text { (This Page) } \\
\text { unclassified }\end{array}$ \\
\hline $\begin{array}{l}\text { (This Report) } \\
\quad \text { unclassified }\end{array}$ \\
\hline 15. NUMBER OF PAGES \\
\hline 16. PRICE \\
\hline
\end{tabular}

